\title{
Effect of community-based interventions targeting female sex workers along the HIV care cascade in sub-Saharan Africa: a systematic review and meta-analysis
}

\author{
Lydia Atuhaire $^{1}$ (D), Olatunji Adetokunboh ${ }^{1,2,3}$, Constance Shumba ${ }^{4,5}$ and Peter S. Nyasulu ${ }^{1,6^{*}}$
}

\begin{abstract}
Background: Female sex workers are extremely vulnerable and highly susceptible to being infected with human immunodeficiency virus. As a result, community-based targeted interventions have been recommended as one of the models of care to improve access to HIV services and continued engagement in care. We conducted a systematic review to (1) assess the effect of FSW-targeted community interventions on the improvement of HIV services access along the treatment cascade and (2) describe community-based interventions that positively affect continuation in HIV care across the HIV treatment cascade for FSWs in sub-Saharan Africa.
\end{abstract}

Methods: We defined the 5 steps that make up the HIV care cascade and categorized them as outcomes, namely, HIV testing and diagnosis, linkage to care, receipt of ART, and achievement of viral suppression. We conducted a systematic search of randomized controlled trials, cohort, and cross-sectional studies done in sub-Saharan African countries and published from 2004 to 2020. The period was selected based on the time span within which ART was scaled up through widespread roll-out of comprehensive HIV programs in sub-Saharan Africa. We reviewed studies with data on the implementation of community interventions for any of the HIV care cascade stage. The data were analyzed using random effects meta-analysis where possible, and for the rest of the studies, data were synthesized using summary statistics.

Results: The significant impact of the community interventions was observed on HIV testing, HIV diagnosis, and ART use. However, for HIV testing and ART use, the improvement was not sustained for the entire period of implementation. There were minimal interventions that had impact on HIV diagnosis, with only one community service delivery model showing significance. Generally, the interventions that had reasonable impact are those that implemented targeted and comprehensive package of HIV services provided at one location, and with unique strategies specific to each cascade stage.

(Continued on next page)

\footnotetext{
* Correspondence: pnyasulu@sun.ac.za

'Division of Epidemiology \& Biostatistics, Faculty of Medicine and Health

Sciences, Stellenbosch University, Cape Town, South Africa

${ }^{6} \mathrm{School}$ of Public Health, Faculty of Medicine and Health Sciences, University

of the Witwatersrand, Johannesburg, South Africa

Full list of author information is available at the end of the article
}

(c) The Author(s). 2021 Open Access This article is licensed under a Creative Commons Attribution 4.0 International License, which permits use, sharing, adaptation, distribution and reproduction in any medium or format, as long as you give appropriate credit to the original author(s) and the source, provide a link to the Creative Commons licence, and indicate if changes were made. The images or other third party material in this article are included in the article's Creative Commons licence, unless indicated otherwise in a credit line to the material. If material is not included in the article's Creative Commons licence and your intended use is not permitted by statutory regulation or exceeds the permitted use, you will need to obtain permission directly from the copyright holder. To view a copy of this licence, visit http://creativecommons.org/licenses/by/4.0/ The Creative Commons Public Domain Dedication waiver (http://creativecommons.org/publicdomain/zero/1.0/) applies to the data made available in this article, unless otherwise stated in a credit line to the data. 


\begin{abstract}
(Continued from previous page)
Conclusions: The evidence brought forward from this review shows that the effect of community-based interventions varies across the different stages of HIV care cascade. A broad package of interventions including a combination of behavioral, biomedical, and structural, designed with specific strategies, unique to each cascade stage appears to be more effective, although information on long-term treatment outcomes and the extent to which FSWs remain engaged in care is sparse. There is need to conduct a further research to deepen the assessment of the effectiveness of community-based interventions on HIV care cascade for FSWs. This will enhance identification of evidence-based optimal interventions that will guide effective allocation of scarce resources for strategies that would have a significant impact on HIV service delivery.
\end{abstract}

Systematic review registration: PROSPERO CRD42020157623

Keywords: HIV interventions, Female sex workers, HIV treatment cascade, HIV care continuum, Sub-Saharan Africa

\section{Background}

Female sex workers (FSWs) are 21 times more susceptible to human immunodeficiency virus (HIV) infection than other adults aged 15-49 years [1]. On average, HIV prevalence among FSWs is estimated to be approximately $12 \%$ globally [2]. Findings from a systematic review of studies conducted in low- and middle-income countries with medium and high HIV prevalence indicated disproportionately high burden of HIV estimated at 12 to $31 \%$ of FSWs living with HIV [3]. In Uganda, HIV prevalence among FSWs is estimated to be 33 to $36 \%$ [4] compared to $5.8 \%$ in the general population [1] and in Nigeria at $24.5 \%$ compared with $4 \%$ among adult population aged 15-49 years [5]. HIV infection among FSWs is due to high prevalence of sexually transmitted infections (STIs) and unsafe sex practices with multiple sexual partners attributed to challenging economic circumstances $[6,7]$. In addition, punitive environments such as violence, criminalization, stigma and discrimination, social and legal obstacles have been shown to limit access to services for HIV prevention, care, and treatment for FSWs $[8,9]$. Various targeted intervention models of care have focused on FSWs with the aim of addressing poor access to HIV services and continued engagement in care [10-13]. In 2016, the World Health Organization (WHO) disseminated consolidated guidelines for key populations including FSWs, with community-based approaches as one of the priority service delivery models [2]. Further, in 2018, the WHO developed a decision framework on differentiated antiretroviral therapy (ART) and, among other strategies, encompassed HIV community responses for FSWs [10]. Among the different types of service provision, community-based service delivery approaches have gained more recognition as an evidence-based intervention to achieve positive health outcomes for FSWs [14, 15]. As such, many HIV/AIDS programs have implemented targeted community service delivery models, and their effectiveness to reducing HIV risk among sex workers has been demonstrated [16, 17].

However, to demonstrate the effectiveness of an HIV intervention depends on the ability to show that a particular intervention can increase access to prevention and treatment services across the treatment cascade [18]. It is therefore critical to measure the performance of community-based interventions across the care and treatment cascade through a series of steps from access to HIV testing and receipt of an HIV-positive diagnosis to successful treatment of their HIV infection. However, such an assessment has not been previously done, despite policy makers' and donors' appeal for HIV/AIDS response partners to evaluate the effectiveness of interventions to guide resource allocation and scale up of high impact and sustainable service delivery models $[19,20]$.

Community-based interventions for FSWs have been assessed in only three previous systematic reviews [14, 17, 21]. The first review aimed to provide evidence on the impact of community empowerment for FSWs on condom use, HIV, and other STI infection. The findings showed that the targeted outcome measure on use of condoms and STI screening was significantly improved due to their association with community-based empowerment approaches [17]. The second review assessed the barriers and facilitators of the implementation of FSW community empowerment programs [14]. The decriminalization of sex work and building of social cohesion among FSWs were identified as facilitators while funding constraints were identified as hindrances to successful implementation. The third systematic review [21] described the nature and structure of targeted community empowerment sexual reproductive health (SRH) interventions and their impact on increased HIV service access for FSW. This review found that, although FSWdedicated clinics had been established in proximity where FSWs lived and worked and somewhat increased access, very few provided a full package of SRH services for FSWs. All these reviews raised concerns regarding the weak quality of the evidence and recommended further research on the impact of community-based HIV interventions.

Based on the literature review findings, the available systematic reviews have mainly focused on SRH services, and it remains unknown how community-based interventions have been impactful across the HIV treatment cascade. 
With the extensive recognition that community-based interventions for FSW are an important strategy in HIV response, it is critical to identify and evaluate the uniqueness of specific interventions that may affect FSWs continuation in HIV care. None of the previous studies has systematically presented measurable outcomes attributed to the FSWs-targeted community-based HIV interventions along the HIV treatment cascade. We conducted a systematic review and meta-analysis to find evidence on the effectiveness of community-based interventions that targeted FSWs across the HIV care cascades as outcomes of interest including HIV testing and diagnosis, linkage to care, receipt of ART, and achievement of viral suppression.

\section{Objectives}

1) To assess the effect of FSW-targeted community interventions on the improvement of HIV service access along the treatment cascade including HIV testing and diagnosis, linkage to care, receipt of ART, and achievement of viral suppression.

2) To describe community-based interventions that positively impact continuation in HIV care across the HIV treatment cascade for FSWs in subSaharan Africa.

\section{Research questions}

1) Do the FSW-targeted community interventions have an effect on the improved HIV services access across the treatment cascade?

2) Which specific community-based interventions are more impactful to the improved HIV service access across the HIV treatment cascade for FSWs in subSaharan Africa?

\section{Methods and design}

The protocol for this systematic review was registered on PROSPERO, CRD42020157623 registration and published [22].

\section{Definition of FSW community-based service delivery}

For the purpose of this systematic review, the terms "community-based service delivery" and "communitybased HIV interventions" were used interchangeably. We utilized a working definition suggested by Moore et al. [21] who defined community-based interventions as services that are provided within geographical areas where FSWs live and work. The community-based services considered in this review were those that had been implemented in various ways including (i) those that provided supportive services to the public health facilities such as linking the clients to the health system for
HIV care, (ii) routine outreach services, (iii) targeted FSW clinics based in hotspots, and (iv) stand-alone community services without a link to the formal public or private health facilities.

\section{Definition of female sex work}

In this review, FSWs were defined as women who selfidentify as sex workers and exchange sex for money, engage in transactional sex, or exchange sex for other gifts and commodities.

\section{Eligibility criteria for considering studies for review}

We included randomized control trials (RCT), crosssectional surveys, and cohort interventions conducted in sub-Saharan African countries from 2004 to 2020. We also reviewed unpublished quantitative data from reports and policy documents published within the region and period. The period was selected based on the time span within which ART was scaled up through widespread roll-out of comprehensive HIV programs in sub-Saharan Africa [20].

\section{Study participants and intervention}

To be included in the review, a study had to have evaluated a community-based HIV intervention for FSWs regardless of age and reported its effectiveness on one or more cascade stages. Studies that reported on community-based HIV services provided for FSWs in addition to other groups were also included if data was disaggregated and reported by sex work status.

\section{Outcomes}

In order to be eligible for inclusion in the review, studies should have measured and reported the performance of the community-based HIV interventions at baseline/ end-line or multi-arm design. Studies that had set performance targets for one or more treatment cascade stage and reported on outcomes post-intervention were also eligible. In this review, the HIV care cascade stages included HIV testing and diagnosis, linkage to care, receipt of ART, and achievement of viral suppression. Although retention in care is one of the cascade stages, it was intentionally not assessed in this review because of a lack of consensus about how to best measure retention or continuity in HIV [23, 24]. The outcomes were defined following one of the two ways CDC monitors the continuum of care [25]. We followed diagnosisbased HIV care continuum definition that shows each step as a percentage of the number of people living with diagnosed HIV.

HIV testing was defined as reported change (increase or decrease) in the number of FSWs that accessed HIV testing in a community-based HIV testing program; HIV diagnosis was defined as the proportion of FSWs 
diagnosed with HIV among those tested; linked to care was defined as the proportion of participants who got diagnosed versus the proportion of those that accessed HIV care services, categorized as the completion of a first medical clinic visit after HIV diagnosis; receipt of ART was defined as the proportion of participants who initiated ART, among those who were diagnosed with HIV; and achievement of viral suppression was defined as the proportion of participants who attained viral suppression among those diagnosed with HIV.

\section{Search strategy}

We used a search strategy for electronic bibliographic databases, bibliographies of included articles, and grey literature sources. We developed a comprehensive set of search terms subjectively and iteratively, checking Medline (PubMed) through September 2020 to identify controlled vocabulary $(\mathrm{MeSH})$ terms related to our topic, and identified keywords based on our knowledge of the field. Medline search terms were adapted for other electronic databases to conform to their search functions. The following electronic databases were searched using the date range 2004 to present: Medline (PubMed), CINAHL (EBSCO Host), Science Citation Index Expanded (SCI-Expanded) and Social Sciences Citation Index (SSCI) both from the Web of Science, Scopus (Elsevier), and Cochrane Library, including the Cochrane Central Register of Controlled Trials (CENTRAL). Websites of Joint United Nations Programme on HIV/AIDS (UNAIDS) and WHO were searched for additional reports of sex work programs. In addition to the electronic search, we searched for grey literature to identify any relevant unpublished reports. We also checked the reference lists of relevant articles for additional citations and used the "related citations" search key in PubMed where we identified similar papers. Search results were managed using specialized bibliographic software (Endnote).

\section{Search terms}

The following terms were entered into all data bases:

HIV Infections[MeSH] OR HIV OR "hiv infect" " OR "human immunodeficiency virus") AND ("HIV treatment cascade" OR "HIV continuum of care") AND ("Community Health Services"[Mesh]) OR "Delivery of Health Care"[Mesh] OR "Health extension worker" or "Community led" OR "Community Implementer" OR "community worker" OR "lay health worker") AND ("Sex Workers"[Mesh] OR "Sex Work"[Mesh] OR prostitut" OR "exchanging sex" OR "sex trade ") AND ("Africa South of the Sahara"[Mesh] OR subsaharan africa*)

\section{Selection of eligible studies}

Titles and abstracts were screened by two reviewers independently (LA, OA) and harmonized the differences by consensus on the studies eligible for full text screening. All full text articles were assessed for relevance by the same two reviewers independently (LA, $\mathrm{OA}$ ), and determined final studies that were eligible for inclusion for the systematic review. Disagreements were resolved by mutual consensus and by consultation with the third reviewer $(\mathrm{PN})$.

\section{Data extraction and management}

Data were extracted using a standardized tool developed based on the Cochrane format data collection form for intervention reviews [26]. The developed tool was piloted by two reviewers (LA, OA) independently on a random sample of two articles, and the tool was revised accordingly. For all eligible studies, the same authors extracted data and jointly reviewed the extracted information for harmonisation. Discrepancies in the extracted data were resolved through discussion, consensus, and involvement of a third reviewer (PN) when necessary. The following data was collected from each included study:

We collected data on study identification which included title, author, and year of publication; and characteristics of studies such as study design, target group, description of interventions, type of comparison, type of outcome measures, unit of allocation (individuals or clusters), period of study, duration of follow-up, setting including country of study (locality and social context), method of participant recruitment, random or nonrandom allocation of participants, baseline imbalances, sample size, and mean age. Other areas for which we collected data on included interventions such as specific type of community-based service delivery interventions per arm where it was applicable and co-interventions. We collected data on outcome measures including number or proportions of FSW outcomes (HIV testing and HIV diagnosis, linked to care, receipt of ART and achievement of viral suppression) at baseline and endline and time points measured. There was also additional information collected on facilitators and challenges of implementing community-based interventions and limitations of the studies.

\section{Assessment of risk of bias}

Risk of bias for randomized controlled trials was assessed using an adapted Cochrane Collaboration's tool for assessing risk of bias. We used the tool to assess sequence generation, allocation concealment, blinding of participants and personnel, blinding of outcome assessment, incomplete outcome data, selective outcome reporting, and other sources of bias [26]. For crosssectional and cohort studies, risk of bias was assessed, and study quality rated using the adapted Newcastle Ottawa scale (NOS) [27]. The Ottawa scale included the following items: (i) representativeness of study sample and ascertainment of the exposure, (ii) comparability of 
cohorts on the basis of the design or analysis controlled for confounders, (iii) outcome assessment and adequacy of follow-up period. Publication bias was assessed by visually inspecting funnel plot asymmetry and by including study size in the logistic model.

\section{Data analysis}

The data were analyzed using random effects metaanalysis. The main characteristics of included studies were synthesized using summary statistics to describe characteristics such as mean (standard deviation) and frequencies. For each step of the cascade together with the extracted community HIV service delivery interventions, the proportions with exact binomial 95\% confidence intervals $(\mathrm{CI})$ were calculated and presented in forest plots.

The homogeneity of the results was calculated by means of the Chi-square test, and the $I^{2}$ was used to describe the percentage variation across included studies. We planned to explore substantial heterogeneity $\left(I^{2}>50 \%\right)$ by subgroup analysis; however, the findings did not warrant this. Metaanalyses with substantial heterogeneous results involve few studies and do not warrant subgroup analysis. All analyses were done in STATA version 16.0 (StataCorp. Stata Statistical Software: release 16. College Station, TX).

\section{Results}

\section{Summary of key findings}

Overall, this review found evidence on the impact of selected community-based intervention packages on FSWs continuation in HIV care across the HIV care cascade. The significant impact of the interventions was observed on three cascade stages namely: HIV testing, HIV diagnosis, and ART use. However, for HIV testing and ART use, the improvement was short-lived in that the retention on ART and improved access to HIV testing was not sustained for the entire period of implementation. There were limited impactful interventions for HIV diagnosis with only one community service delivery model showing significance. Generally, impactful interventions were those that implemented targeted and comprehensive package of HIV services provided at one location within places where FSWs worked and lived, and with unique service delivery models for specific cascade stages. This review also found that communitybased interventions led to the improvement of linkage to care and viral load suppression to undetectable levels; however, the improvement was not significant. In addition, the results showed that many of the projects were small-scale, research-based, and have limited timebound implementation periods. A few non-research based and large-scale HIV prevention efforts had limited systematic means of monitoring outcomes along the HIV care cascade and therefore, less methodical attention to constantly reviewing the effectiveness of interventions and altering delivery strategies accordingly.

\section{Characteristics of included studies}

Our literature search yielded 582 articles, and after removing duplicates, we remained with 565 studies. Following screening of the titles and abstracts, we retained 45 studies for full text review. After thoroughly reading the remaining 45 articles, 27 studies were excluded for the following reasons: six articles had reported outcomes that did not meet our eligibility criteria, six did not meet the study design criteria, eight studies had not reported community based interventions, two articles were not written in English, two had either not targeted FSWs or not reported disaggregated data for FSWs, two articles were abstracts from conferences and we failed to access the required information, and one had not been conducted in Sub-Saharan Africa (Fig. 1).

The remaining 18 studies were found eligible for inclusion in the review (Table 1). The study designs were randomized controlled trials $(n=3)$, cross-sectional studies $(n=10)$, and cohort studies $(n=4)$ and quasiexperimental study $(n=1)$. These studies were conducted in seven sub-Saharan African countries (Table 1). Most of the included studies were from Zimbabwe $(n=$ 5) $[30-32,40,41]$, Tanzania $(n=3)[35,44,45]$, and Kenya $(n=2)[34,39]$, and 5 studies of which each was from Guinea $(n=1)$ [28], Zambia $(n=1)$ [29], Burkina Faso $(n=1)$ [33], Uganda $(n=1)$ [42], and South Africa $(n=1)$ [43].

There were two multi-country studies conducted in Burundi, Cote d'Ivoire, and DRC $(n=1)$ [37], and South Africa, Mozambique, and Kenya $(n=1)$ [36]. All studies in the review were conducted among FSWs, with two studies that included non FSWs and MSM. The first study compared uptake of HIV services among FSW and non-FSW [33], and the second one also included MSM [37] but reported disaggregated results for FSW.

The common implementation models of community interventions included (i) promotion of FSW participation with client-led approach, (ii) intense community mobilization approaches through direct service delivery to places where FSW live and work, and (iii) application of technological innovation (i.e., text messaging) as a tool for mobilization of increased uptake of HIV services. Other interventions also focused on provision of comprehensive package of services using a one-stop shop approach in the community, peer-to-peer implementation approaches, and provision of static services in clinics based in hotspots of FSWs.

The vast majority of the studies focused on traditional FSW service delivery approaches that included peerfocused approach of mobilization, condom promotion, HIV testing, and promotion of regular STI screening 


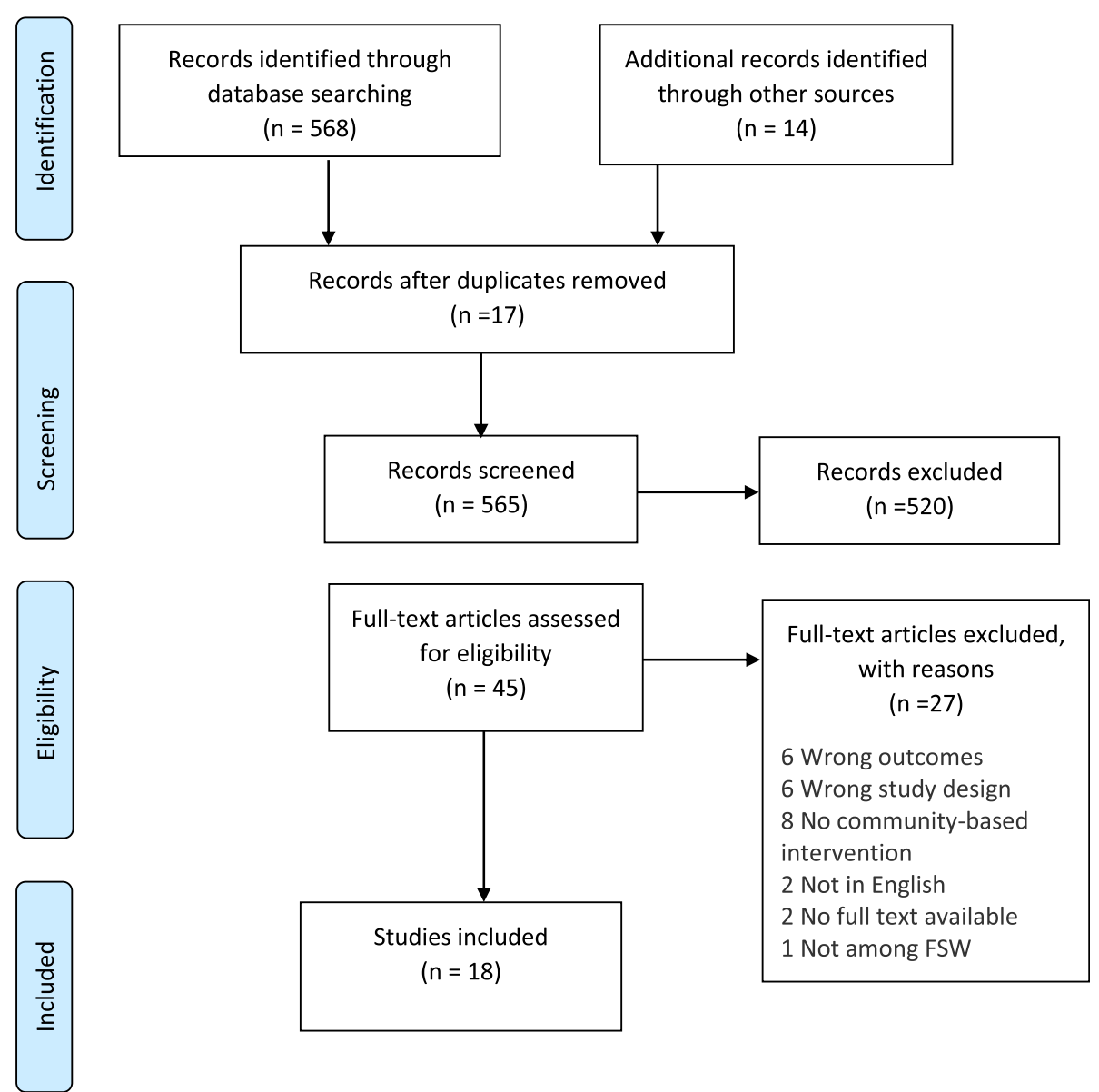

Fig. 1 PRISMA flow diagram of selection process

(Table 2). Only six studies measured at least two or more HIV cascade outcomes downstream of HIV testing to viral suppression among FSWs at the end of the implementation period of the community-based interventions [28-30, 35, 36, 41].

\section{Risk of bias in included studies The risk of bias in the included RCTs}

Selection bias of allocation sequence generation was low in two studies and unclear in the remaining two. Allocation of concealment was unclear in three studies and low in one. In two RCTs, blinding of participants and personnel and blinding of outcome assessment was low and unclear in the remaining two studies. The risk of reporting incomplete data due to attrition and selective outcome reporting was low in three studies, high in one study, and unclear in one study. The risk of bias in all RCTs was highest due to other forms of bias such that all had high risk due to reliance on self-report for outcomes and short periods of intervention implementation with uncertain population effect. Other risk of bias were also related to low sample sizes including testing the intervention on limited number of FSW and FSW communities.

\section{The risk of bias assessment in cohort studies}

One cohort study had low risk of bias in relation to selection of representative samples and justification for case and control selection. However, for two cohort studies, the risk of bias was unclear as information on justification for selection of control and cases was not provided. Never the less, both studies demonstrated that participants were not exposed to the intervention before the start of the study. All cohort studies had adequate measures of outcome assessment by using validated measurement scales, measurement of ART use by pill count rather than self-report, and had relatively long follow-up periods of 6 to 12 months.

\section{The risk of bias for cross-sectional studies}

All the nine included cross-sectional studies had low risk of bias in regard to selection of sample size and its 
Table 1 Characteristics of selected studies

\begin{tabular}{|c|c|c|c|c|}
\hline $\begin{array}{l}\text { (\#Ref) } \\
\text { Author } \\
\text { (year) }\end{array}$ & Country & Study aim & Study design & Sample size and participant selection \\
\hline $\begin{array}{l}\text { [28] Aho } \\
\text { et al. } \\
(2012)\end{array}$ & Guinea & $\begin{array}{l}\text { To describe the acceptability and } \\
\text { consequences of VCT among a stigmatized } \\
\text { and vulnerable group, female sex workers } \\
\text { (FSWs), in Conakry, Guinea }\end{array}$ & Cross-sectional study & $\begin{array}{l}\text { Randomly selected } 421 \text { at FSW at baseline } \\
\text { and } 223 \text { at end line. Recruited through } \\
\text { private or public centers providing adapted } \\
\text { healthcare services (AHS) for FSWs }\end{array}$ \\
\hline $\begin{array}{l}{[29]} \\
\text { Chanda } \\
\text { et al. } \\
\text { (2017) }\end{array}$ & Zambia & $\begin{array}{l}\text { To evaluate the effect of } 2 \text { different health } \\
\text { system mechanisms (the active approach of } \\
\text { peer-based HIV self-test) for HIV self-test de- } \\
\text { livery compared to referral to standard HIV } \\
\text { testing }\end{array}$ & $\begin{array}{l}\text { A 3-arm 1:1:1 cluster random- } \\
\text { ized trial }\end{array}$ & $\begin{array}{l}\text { Total randomized per arm }(320,316 \text { and } \\
\text { 329). Peer educator recruitment of social } \\
\text { network via direct contact and referral }\end{array}$ \\
\hline $\begin{array}{l}{[30]} \\
\text { Cowan } \\
\text { et al. } \\
\text { (2019) }\end{array}$ & Zimbabwe & $\begin{array}{l}\text { (i) To present the current impact that } \\
\text { engagement in the Sisters program has on } \\
\text { HIV incidence, prevalence, and control in } \\
\text { FSW. (ii) To describe the patterns and } \\
\text { characteristics of sex work among FSW in }\end{array}$ & Cross-sectional study & $\begin{array}{l}\text { Use of program data of } 5083 \text { FSW recruited } \\
\text { through respondent-driven sampling sur- } \\
\text { veys through three studies conducted in } 19 \\
\text { sites: in } 2011 \text { to 2015; } 2013 \text { to } 2016 \text { and } \\
2017\end{array}$ \\
\hline
\end{tabular}

Zimbabwe

(iii) To assess the potential for wider population impact of sex worker program by modelling the impact on HIV incidence of eliminating transmission through FSW

[31] Zimbabwe $\quad \begin{aligned} & \text { To describe the HIV diagnosis and care } \\ & \text { cowan }\end{aligned}$
et al.
(2017)

To assess the efficacy of a targeted combination intervention for female sex workers in Zimbabwe.

et al.

(2018)

[33] Huet Burkina Faso et al. (2011)

[34] Kelvin Kenya
et al.
(2019)

[35] $\quad$ Tanzania
Kerrigan
et al.
(2019)

[36] Lafort South Africa, To enhance uptake of SRH services by et al. Mozambique, FSWs through an implementation study (2018) and Kenya

[37] Lillie Burundi, Cote To identify KP that had a new HIV diagnosis et al. d'lvoire, and (2019) DRC

[38] Lafort South Africa, et al. Mozambique, (2016) and Kenya

[39] Kenya Luchters Kenya et al.

To describe the long-term virological, immunological, and mortality outcomes of providing highly active antiretroviral therapy (HAART) with strong adherence support to HIV-infected female sex workers (FSWs) in Burkina Faso and contrast outcomes with those obtained in a cohort of regular HIV-infected women.

To assess whether informing female sex workers about the availability of HIV selftesting at clinics in Kenya using text messages would increase HIV testing rates

To determine the impact of a community empowerment model of combination HIV prevention (Project Shikamana) among female sex workers (FSW) in Iringa, Tanzania. so that they could be linked to life-saving treatment for epidemic control

To identify gaps in the use of HIV prevention and care services and commodities for female sex workers with the aim of improving SRH services.

To evaluate the impact of 5 years of peermediated STI/HIV prevention interventions among FSW in Mombasa, Kenya
Quasi-experimental study
Cross-sectional study

Cohort study

Cluster-randomized trial from 2014 to 2016

A prospective observational study nested within the Yerelon open cohort of highrisk women through a network of peer educators and followed up at a dedicated clinic located within a public health facility.

A prospective communityrandomized trial conducted in 2 communities matched on population size

Cross-sectional study (in the context of an implementation research project)

Respondent-driven sampling surveys of FSW in 14 sites. Recruited 2722 women, approximately 200 per site as the baseline for a cluster-randomized controlled trial investigating a combination HIV prevention and care package.

Randomly assigned 14 clusters (1:1) to receive usual care cluster $(n=3612)$ and an intervention cluster $(n=4619)$

47 FSWs and 48 non-FSWs recruted

A sample of 2196 female sex workers selected from electronic records.

Identified all active sex work venues (164 in total) in the 2 study communities and enrolled 496 FSW through a time-location sampling

400 FSWs recruited by respondent-driven sampling

929 FSWs sampled. Selection was done through distribution of coupons by peer

Cross-sectional survey (in the Used RDS to recruit 400 sex worker in context of an implementation research project)

Pre- and post- intervention cross-sectional surveys
Durban, 308 in Tete, 400 in Mombasa, and 458 in Mysor

Initial respondents (seeds) were identified from FSW work places, with subsequent participants recruited using snowball 
Table 1 Characteristics of selected studies (Continued)

\begin{tabular}{|c|c|c|c|c|}
\hline $\begin{array}{l}\text { (\#Ref) } \\
\text { Author } \\
\text { (year) } \\
\end{array}$ & Country & Study aim & Study design & Sample size and participant selection \\
\hline$(2008)$ & & & & sampling. \\
\hline $\begin{array}{l}{[40]} \\
\text { Napierala } \\
\text { et al. } \\
(2018)\end{array}$ & Zimbabwe & $\begin{array}{l}\text { (1) To compare engagement in services } \\
\text { and the HIV care cascade among FSWs } \\
\text { aged } 18-24 \text { years compared with those } \\
\text { aged } 25 \text { years and older. } \\
\text { (2) To explore factors associated with } \\
\text { young FSWs' engagement in HIV services. }\end{array}$ & Cross-sectional survey & $\begin{array}{l}\text { Sampled } 2722 \text { FSW through respondent- } \\
\text { driven sampling from } 14 \text { communities }\end{array}$ \\
\hline $\begin{array}{l}{[41]} \\
\text { Ndori- } \\
\text { mharadze } \\
\text { et al. } \\
\text { (2018) }\end{array}$ & Zimbabwe & $\begin{array}{l}\text { To compare key indicators related to FSW } \\
\text { health-seeking behavior in } 2011 \text { and } 2015 \\
\text { in three sites and explore whether ob- } \\
\text { served differences might be linked to the } \\
\text { delivery of intensified community } \\
\text { mobilization. }\end{array}$ & Cross-sectional study & $\begin{array}{l}870 \text { FSW sampled in } 2011 \text { and } 915 \text { in } 2015 \text {. } \\
\text { FSWs were selected as seeds of the } 2015 \\
\text { RDS survey, and also reviewed program } \\
\text { data from the Sisters' clinics between } 2010 \\
\text { and } 2015 \text {. }\end{array}$ \\
\hline $\begin{array}{l}{[42]} \\
\text { Pande } \\
\text { et al. } \\
(2019)\end{array}$ & Uganda & $\begin{array}{l}\text { To assess preference and uptake of the } \\
\text { current community-based HIV testing ser- } \\
\text { vice delivery models that are used to reach } \\
\text { FSW and identify challenges faced during } \\
\text { the implementation of the models. }\end{array}$ & Cross-sectional study design & $\begin{array}{l}\text { Used cluster sampling for hotspot selection } \\
\text { and recruited } 72 \text { FSWs in each cluster }\end{array}$ \\
\hline $\begin{array}{l}{[43]} \\
\text { Schwartz } \\
\text { et al. } \\
(2017)\end{array}$ & South Africa & $\begin{array}{l}\text { To assess engagement in the HIV care } \\
\text { cascade and correlates of ART use among a } \\
\text { sample of South African FSWs. }\end{array}$ & Cross-sectional study & $\begin{array}{l}\text { Selection was done through RDS by } \\
\text { selecting seeds to represent FSWs across } \\
\text { ages, race, and locations }\end{array}$ \\
\hline $\begin{array}{l}\text { [44] Tun } \\
\text { et al. } \\
\text { (2019) }\end{array}$ & Tanzania & $\begin{array}{l}\text { To examine differences in treatment } \\
\text { outcomes between the intervention and } \\
\text { comparison arms. }\end{array}$ & $\begin{array}{l}\text { Quasi-experimental } \\
\text { prospective cohort study }\end{array}$ & $\begin{array}{l}309 \text { (intervention) and } 308 \text { (comparison) } \\
\text { sampled at baseline. FSW selected } \\
\text { randomly through community-based HTC } \\
\text { in hotspots, directly contacting former Sauti } \\
\text { FSWs and use of brochures }\end{array}$ \\
\hline $\begin{array}{l}{[45] \mathrm{Vu}} \\
\text { et al. } \\
(2020)\end{array}$ & Tanzania & $\begin{array}{l}\text { To increase linkage to and retention in } \\
\text { antiretroviral therapy (ART) care, by piloting } \\
\text { a community based, ART service delivery } \\
\text { intervention for female sex workers }\end{array}$ & $\begin{array}{l}\text { Quasi-experimental } \\
\text { prospective cohort study }\end{array}$ & $\begin{array}{l}309 \text { (intervention) and } 308 \text { (comparison) } \\
\text { followed from baseline. FSW selected } \\
\text { randomly through; community-based HTC } \\
\text { in hotspots, directly contacting former Sauti } \\
\text { FSWs and use of brochures }\end{array}$ \\
\hline
\end{tabular}

representativeness. However, the overall score between studies varied, but the scoring grades weighed within the acceptable range of 4 to 6 . In regard to risk of bias of assessing whether confounding factors were controlled, this information was not indicated in all the studies apart from one cross-sectional study which reported that post hoc pairwise comparison tests were conducted with RDS-adjusted weights while adjusting for the confounding effect. Lastly, one study did not describe outcome assessment; therefore, its risk of bias was unclear. However, in the rest of eight cross-sectional studies, risk of bias for outcome assessment was low as there was adequate description of the validated measures used to control for risk of bias. These included reviews of medical records and health assessment by qualified staff among others. All studies used statistical tests to control for bias in individual studies.

\section{HIV testing services}

HIV testing was done in two randomized control studies conducted in Kenya [34] and Zambia [29].
The participants in the intervention arms for both studies were more likely to test for HIV than the standard of care arms. At 1 month's follow-up, Chanda et al. [29] registered $94.9 \%$ of HIV testing; however, the testing rates dropped to $84.1 \%$ at 4 months of follow-up in the intervention arm. Similarly, in an RCT [34], participants in the intervention arm were significantly (OR 1.9, $p=0.001$ ) more likely to test for HIV, $(81,10.8 \%)$ compared to those in the enhanced standard of care $(46,6.1 \%)$ and usual standard of care $(43,6.2 \%)$ (OR $1.0(p=0.972))$.

Three cross-sectional studies also reported HIV testing as an outcome $[28,36,42]$. In a study conducted in Guinea [28] where adapted HIV care services were provided to FSW, there was $100 \%$ acceptance to HIV testing although there were reports of coercion by managers of FSW worksites affecting voluntary consent for an HIV test. Equally, Lafort et al. [36] conducted context-specific targeted community intervention in three cities: Durban in South Africa, Tete in Mozambique, and Mombasa in Kenya. In all the three cities, among all services 
Table 2 A summary table showing impact of community HIV intervention on continuation in HIV care across the treatment cascade, extracted from the included studies

\begin{tabular}{|c|c|c|}
\hline Cascade step & Combined interventions that showed significant impact & Evidence \\
\hline HIV testing & $\begin{array}{l}\text { - Partnership with KP NGOs/CBOs based in the community/hotspots to deliver HTS services on behalf of } \\
\text { national programs } \\
\text { - Peer educator direct distribution of HIV self-test kits } \\
\text { - Repeated use of text messaging and communication on what's up by peers informing FSW about the } \\
\text { availability of testing services in the community } \\
\text { - Adapted health care: creation of FSW safe spaces and integration of targeted FSW HIV services in the } \\
\text { general health care (e.g., STI screening and treatment, lubricants and condoms, direct escort by FSW } \\
\text { peers within a public facility) } \\
\text { - Provision of testing through night clinics (bars, brothels, DICs) } \\
\text { - Full time provision of testing at clinics based in hotspots } \\
\text { - Strengthening support networks FSW CSOs to encourage health-promoting behavior } \\
\text { - Venue-based peer education, free condom distribution, and HIV counseling and testing; }\end{array}$ & $\begin{array}{l}\text { Chanda et al. [29] } \\
\text { Kelvin et al. [34] } \\
\text { Aho et al. [28] } \\
\text { Lafort et al. [38] } \\
\text { Pande et al. [42] }\end{array}$ \\
\hline HIV diagnosis & $\begin{array}{l}\text { Enhanced peer outreach approach: } \\
\text { - Use of paid outreach peers that have not worked as peers before to find new FSWs from their network } \\
\text { - Use of short-term incentivized peer support to reach their hard to reach contacts-FSWs }\end{array}$ & Lillie et al. [37] \\
\hline $\begin{array}{l}\text { Linkage to } \\
\text { care }\end{array}$ & None & \\
\hline ART use: & $\begin{array}{l}\text { - NGO-initiated FSW-targeted mobile clinical services } \\
\text { - Provision of services at a community-led drop-in center } \\
\text { - Training of health workers in FSW-friendly approaches } \\
\text { - Provision of HIV services in the community clinic by a professional health provider } \\
\text { - Extending operating days at community based clinics with flex working hours } \\
\text { - Provision of broad package of HIV service offered in clinics based in hotspots } \\
\text { - Provision of on call services where FSW can consult anytime } \\
\text { - Police sensitivity trainings, violence prevention, and campaigns for anti-stigma and discrimination }\end{array}$ & $\begin{array}{l}\text { Kerrigan et al. [35] } \\
\text { Cowan et al. [32] } \\
\text { Napierala et al. [40] } \\
\text { Pande et al. [42] }\end{array}$ \\
\hline $\begin{array}{l}\text { Viral } \\
\text { suppression }\end{array}$ & None & \\
\hline \multicolumn{3}{|c|}{ Interventions that showed a positive effect but with non-significant impact } \\
\hline Linkage to & $\begin{array}{l}\text { - Enhancing referral mechanisms to the neighboring public health facilities by paying stipend for peers. } \\
\text { - Financial facilitation of FSW focal persons based at public health facilities } \\
\text { - Establishment and incentivized peer referrals to the DICs } \\
\text { - Creation of a safe space at a public health facility in a community without a FSW DIC } \\
\text { - Conducting sensitivity trainings to all service providers including the non-professional staff within the } \\
\text { - clinics } \\
\text { - Peer referrals and linkages at the clinics based in hotspots } \\
\text { - Behavior change communication to educate and improve health-seeking behaviors } \\
\text { - Extended hours of work to evenings, night, and weekends } \\
\text { - Mobile HIV services to mitigate transport issues }\end{array}$ & $\begin{array}{l}\text { Chanda et al. [29] } \\
\text { Kerrigan et al. [35] Pande } \\
\text { et al. [42] } \\
\text { Lafort et al. [36] }\end{array}$ \\
\hline $\begin{array}{l}\text { Viral } \\
\text { suppression: }\end{array}$ & $\begin{array}{l}\text { - Usual HIV services augmented with additional community mobilization activities aimed at raising } \\
\text { awareness of the benefits of ART. } \\
\text { - Building leadership skills among FSW groups } \\
\text { - Participation of FSW groups in selecting their fellow FSW adherence supporters } \\
\text { - Adherence training sessions for the FSW adherence supporters } \\
\text { - Mobile telephone messaging reminders for ART adherence } \\
\text { - SMS and follow-up phone to support clinic attendance. } \\
\text { - Empowering FSW to improve retention in care by targeting improved individual client-oriented } \\
\text { practices }\end{array}$ & $\begin{array}{l}\text { Cowan et al. [32] } \\
\text { Kerrigan et al. [35] } \\
\text { Napierala et al. [40] }\end{array}$ \\
\hline
\end{tabular}

provided, the greatest effect was on uptake of HIV testing, increasing from 40.9 to $83.2 \%$ in Durban, 56.0 to $76.6 \%$ in Tete, and 70.9 to $87.6 \%$ in Mombasa. Finally, a cross-sectional study [42] conducted in Uganda compared three models of community interventions and assessed model preference determined by increased access and utilization of HIV testing services. This study showed that static clinics based in FSW hotspots were preferred $(72 \%(279 / 390))$ compared to $25 \%(98 / 390)$ that used outreaches and 3.3\% (13/390) that used peerto-peer mechanisms to have an HIV test. These models were implemented and assessed over a period of 12 months.

\section{HIV diagnosis}

HIV diagnosis was measured in six cross-sectional studies [28, 39-43], two randomized controlled trials [29, 32], and one quasi-experimental study [37]. The quasi- 


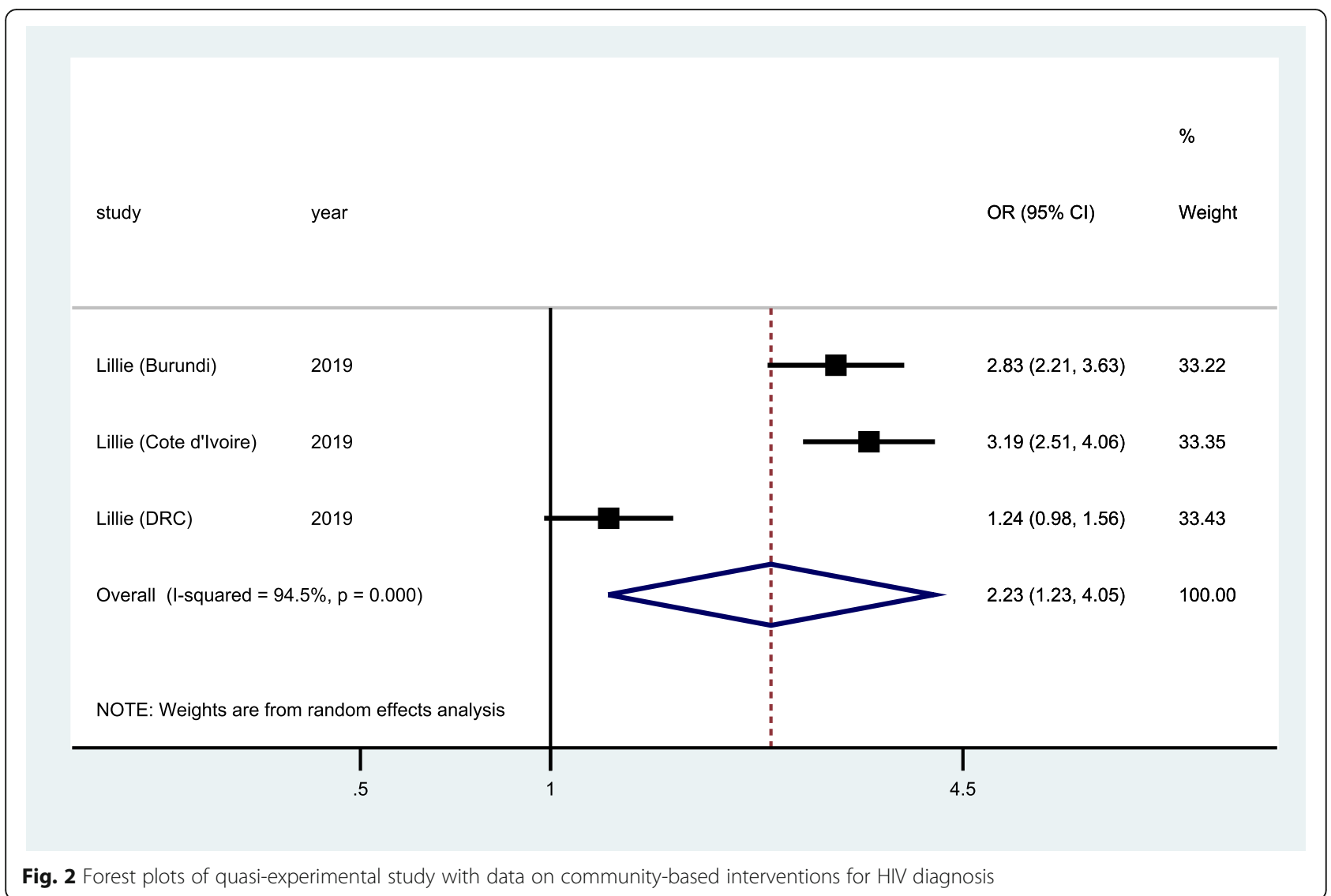

experimental study (Fig. 2) was conducted in three different countries (Burundi, Cote d'Ivoire, and DRC) and measured the proportions of people living with HIV during the implementation of an enhanced peer outreach approach (EPOA) for the three countries. Pooled analysis of data from the three countries showed statistically significant increase in proportion of participants diagnosed with HIV (OR 2.23; 95\% CI 1.23$4.05 ; p<0.001)$. However, pooled analysis of data from two RCTs (Fig. 3) that randomized participants to standard of care testing versus general peer support augmented with additional community mobilization showed that there was no significant improvement in HIV diagnosis among FSWs (OR 0.99; 95\% CI 0.79-1.24; $p=0.307$ ). Similarly, data from the pooled analysis of three cross-sectional studies (Fig. 4) showed that there was a reduction in HIV diagnosis tending towards the negative impact, although this was not statistically significant $(\mathrm{OR}=0.96 ; 95 \% \mathrm{CI} 0.84-1.11 ; p=$ $0.554)$. The community-based interventions comprised of peer-mediated service delivery to improve access of HIV services, intensified community mobilization, and integrated adapted health services to suit specific needs of FSW.

\section{Linkage to care}

Two RCTs [29, 35] and two cross-sectional studies $[42,43]$ reported linkage to care as an outcome. The data from pooled analysis of RCTs showed that there was improved linkage to care showing a tendency towards a positive impact of the intervention for the FSW who were provided with services in communityled drop-in centers, through venue-based peer education, introduction of social support, and text messages to promote solidarity and engagement. Nonetheless, this was not statistically significant (OR 2.03; 95\% CI 0.87-4.77; $p=0.085$ ) (Fig. 5). The data of pooled analysis from the cross-sectional studies showed that there was a $65 \%$ improvement in linkage to care (overall estimate $=0.65 ; 95 \%$ CI $0.60-0.69 ; p=0.000$ ). This was observed at the end of the follow-up period of implementing health worker-led HIV service delivery in clinics based in hotspots and outreaches in community settings as well as peer-to-peer mechanism (Fig. 6).

\section{Use of antiretroviral therapy and retention in care}

ART use was measured in three RCTs [29, 32, 35] and three cross-sectional studies [40, 42, 43]. One of 


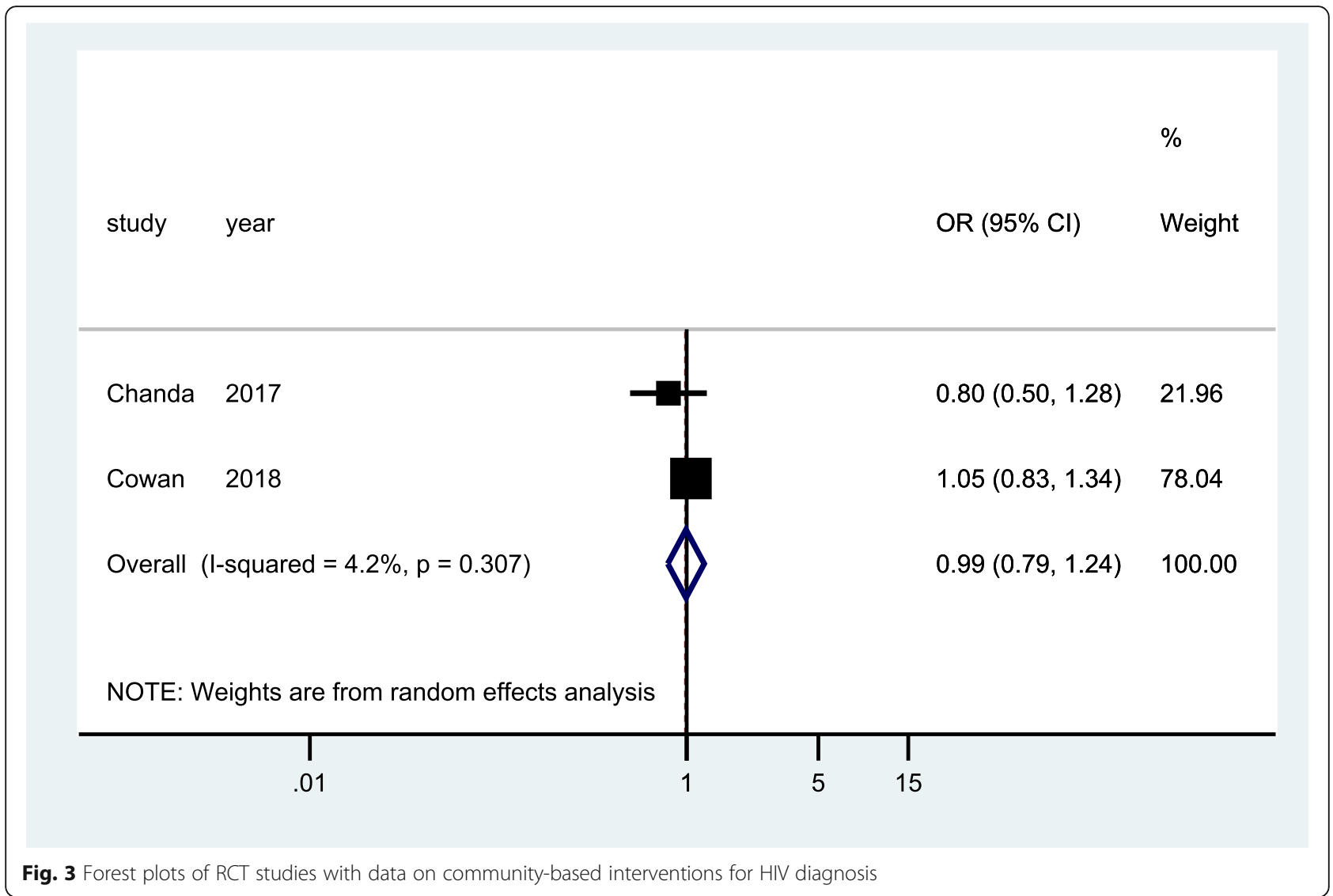

the RCTs had a two-time point measurement at 1 month and 4 months of ART initiation [29] with 1 year of follow-up period, while the two RCTs [32, 35] had a 2-year follow up period with two-time point measurement at 0 months and 18-24 months. The data from pooled analysis of the three RCTs showed significant increase in odd of ART use (OR 1.72; 95\% CI 1.31-2.25) at the start of the implementation of the intervention (Fig. 7) and a much higher increases in odds of ART use at the end of the follow-up period (OR 2.21; 95\% CI 1.38-3.53). No heterogeneity was observed in both analyses (Figs. 7 and 8). The data from pooled analysis of three cross-sectional studies showed a $60 \%$ improvement of ART use with statistical significance $(95 \%$ CI $0.41-0.78, p<0.001)$ (Fig. 9). However, there was evidence of significant heterogeneity between studies $\left(I^{\wedge} 2=97.45 \%\right)$, as such we need to interpret these results with caution. The community intervention implemented for crosssectional studies encompassed provision of targeted HIV services for FSW with augmented additional community mobilization activities and strengthened support networks.

\section{Viral suppression}

Viral suppression was reported in three studies, two RCTs [32, 35] and one cross-sectional study [46]. All the three studies reported data during implementation, while one RCT also reported effect at the end of follow-up period [35]. The RCT by Cowan et al. [32] reported viral suppression rates for the participants that were assigned to clusters of usual care and those of the intervention clusters. At the end of the assessment period, $72 \%(588 / 828)$ in the intervention cluster showed minimal difference in reduction of viral load to undetectable level less than 1000 copies per $\mathrm{mL}$, compared with $68 \%(590 / 869)$ of the participants in the usual care clusters. Similarly, in the RCT by Kerrigan et al. [35], the viral suppression rates showed slight improvement in the intervention group $40.0(n=36)$ to $50.6 \%(n=46)$ compared to the control group $35.9(n=28)$ to $47.4 \%(n=36)$ at the end of 18-month follow-up period. For the cross-sectional study [40], viral suppression was reported separately for young women aged 18-24 years and older women aged $\geq 25$. Among the older FSW, $79 \%$ showed viral load suppression to undetectable level compared to 


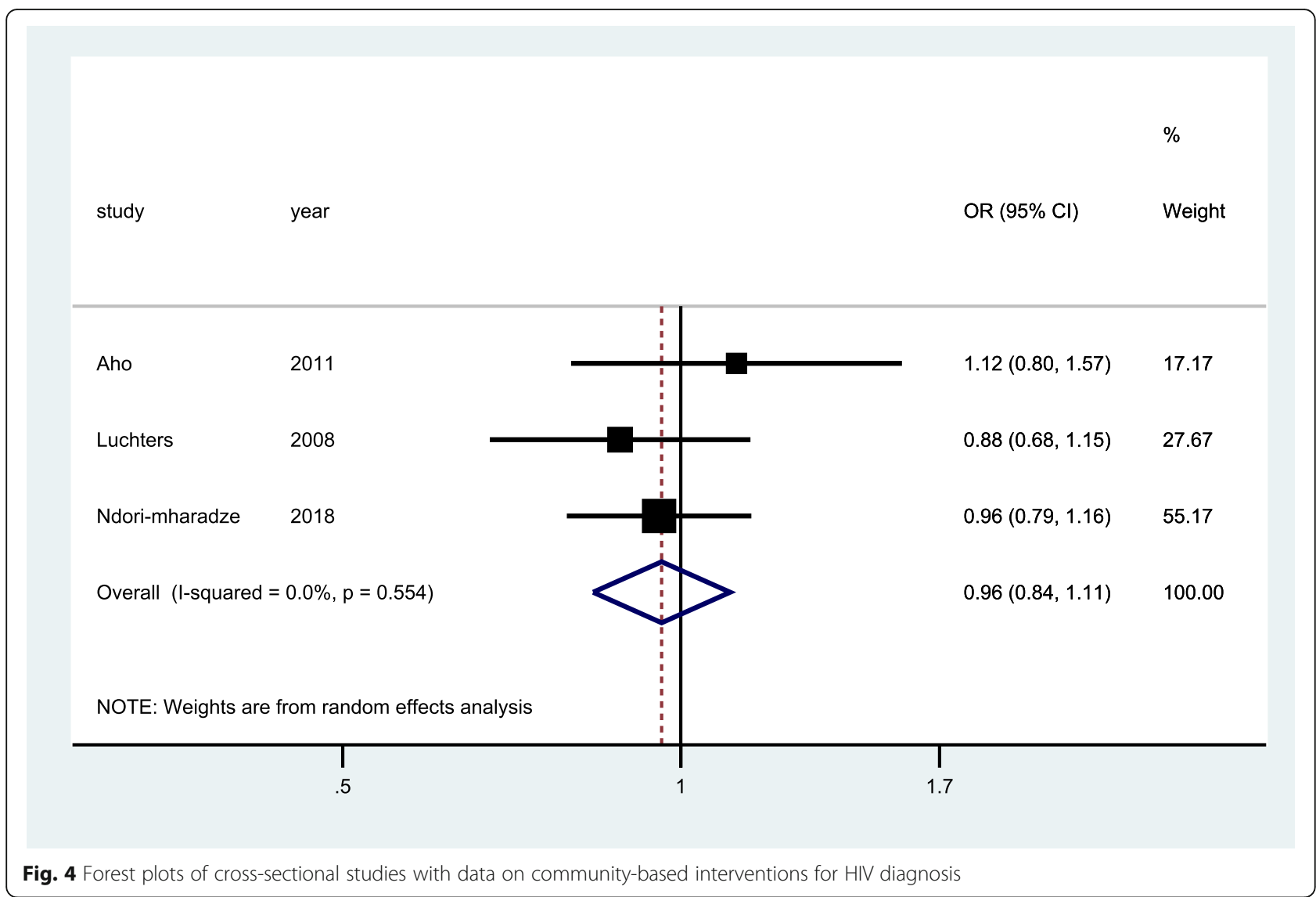

the $62 \%$ of younger FSW, after both groups received targeted HIV services [46].

\section{Discussion}

The objective of this systematic review was to gather evidence on the effectiveness of community-based interventions that provided HIV services to FSWs across the HIV care cascade in sub-Saharan Africa. We aimed to describe the community-based interventions that contributed to the proportions of FSW who tested for HIV, got diagnosed and linked to care, initiated on ART, and achieved viral suppression. Overall, this review found significant evidence on the impact of some community-based intervention packages on improved HIV testing, HIV diagnosis, and ART use. In the pooled analysis of all types of studies included in this review, we documented nonsignificant improvement in linkage to care and viral load suppression (Table 3). Many of the interventions were small-scale, research-based, and with limited time-bound implementation periods. A few nonresearch based and large-scale HIV prevention efforts had limited systematic means of monitoring outcomes along the HIV care cascade and therefore less methodical attention to constantly reviewing the effectiveness of interventions and altering delivery strategies accordingly.

\section{HIV testing}

The findings from this review on HIV testing show that community-based interventions which increased access to HIV testing are those that applied combined strategies such as incentivized peer network referrals, intensified FSW mobilization, structured follow-up to improve repeat testing, integrated health services adapted to specific needs of FSWs such as placing lubricants in clinics, and testing in static clinics based in hotspot [28, 29,34]. The trend of improvement, however, was short-lived with proportions of testing reducing from 95 to $84 \%$ in just 4 months [29] and from 92 to $53 \%$ at 1 year follow-up [28]. According to these studies, the possible explanation for reduced proportions in testing over time was the saturation in target areas. However, the testing guidelines [2] indicate that FSWs should test every 3 months; therefore, the explanation of saturation may not be satisfactory. There is need to investigate why the effectiveness of such interventions 


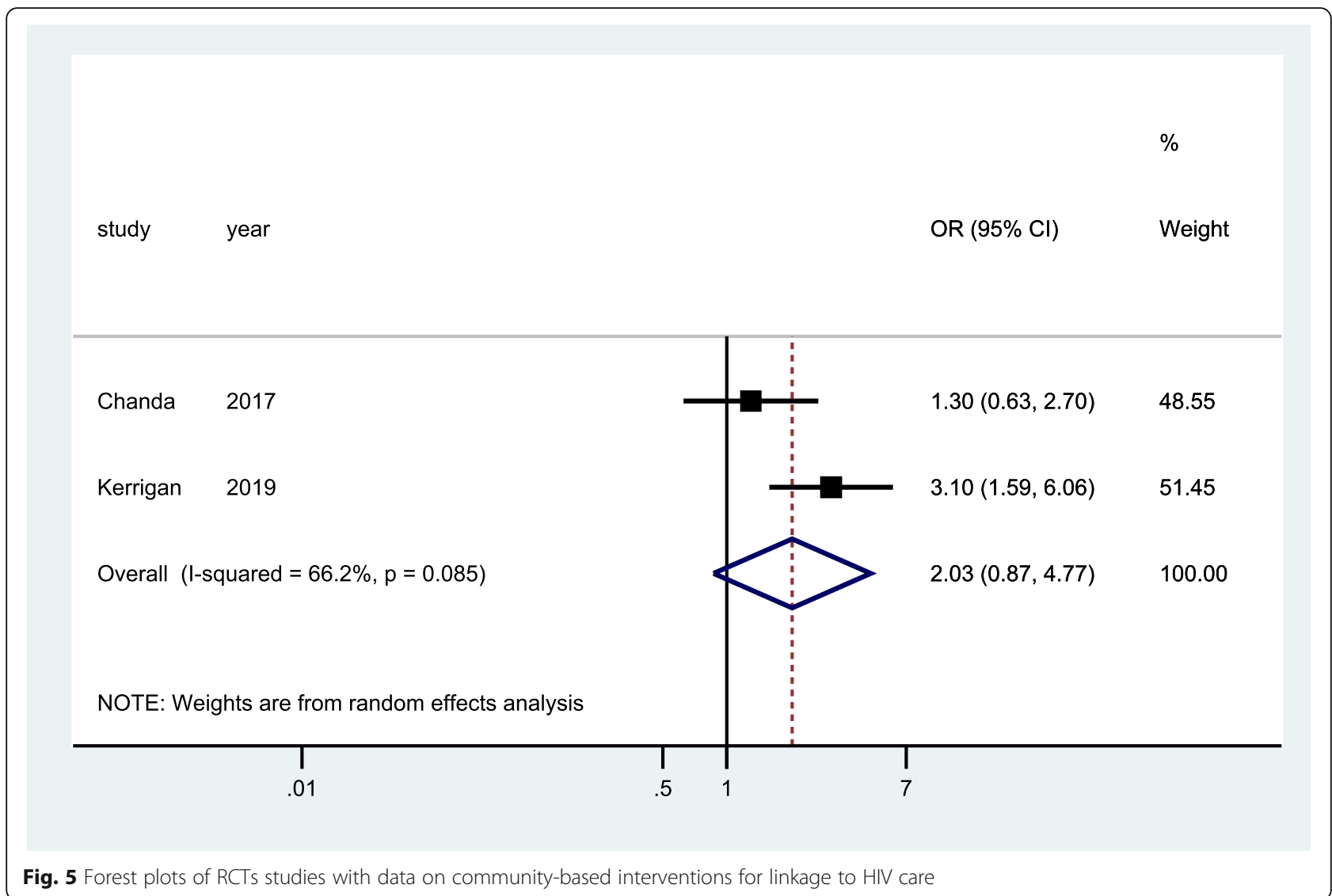

may not be sustained to create opportunities for designing optimal interventions.

This review complements other studies [48-50] which showed that strategies may not work separately but rather are more effective when combined. In this review, all studies whose control groups did not have any enhanced strategies, did not realize improved HIV testing access [29, 34] although the rate of impact was the same across all interventions at the end of the follow-up period [29].

\section{HIV diagnosis}

In regard to HIV diagnosis, the intervention that significantly identified more undiagnosed FSWs is the enhanced peer outreach model. This model involved training the FSWs that were naïve to peer network activities and used them to mobilize from their networks [37]. All the other studies in this review used the enhanced interventions similar to the ones used for HIV testing; however, there was no increase in HIV diagnosis [28, 29, 32, 39, 41].

The findings in this review are related to other studies conducted in Ukraine [51] and Malawi [52], though these were conducted in the general population. Both studies used the newly diagnosed patients to refer people in their networks for testing, and the HIV diagnosis results were promising. With this finding, we emphasize that interventions are unique and may impact cascade stages differently. Therefore, to maximize impact, service delivery models need to be routinely monitored and reviewed to ascertain their effectiveness and revise the strategies accordingly.

\section{Linkage to care}

In this review, we have documented that the data from pooled analysis showed no significant improvement in linkage to care. However, we note that programs that had a positive effect on linkage are those that provided a combination package of HIV services delivered in areas with close proximity to high concentrations of FSWs such as hotspots and drop-in centers alongside extended working hours during evenings, weekends, and those that carried out sensitivity training for all the service providers [35, 42]. Previous reviews have indicated that, for optimal linkage to care, FSWs need to access comprehensive HIV services alongside structural interventions. Such structural interventions include those that focus to address 


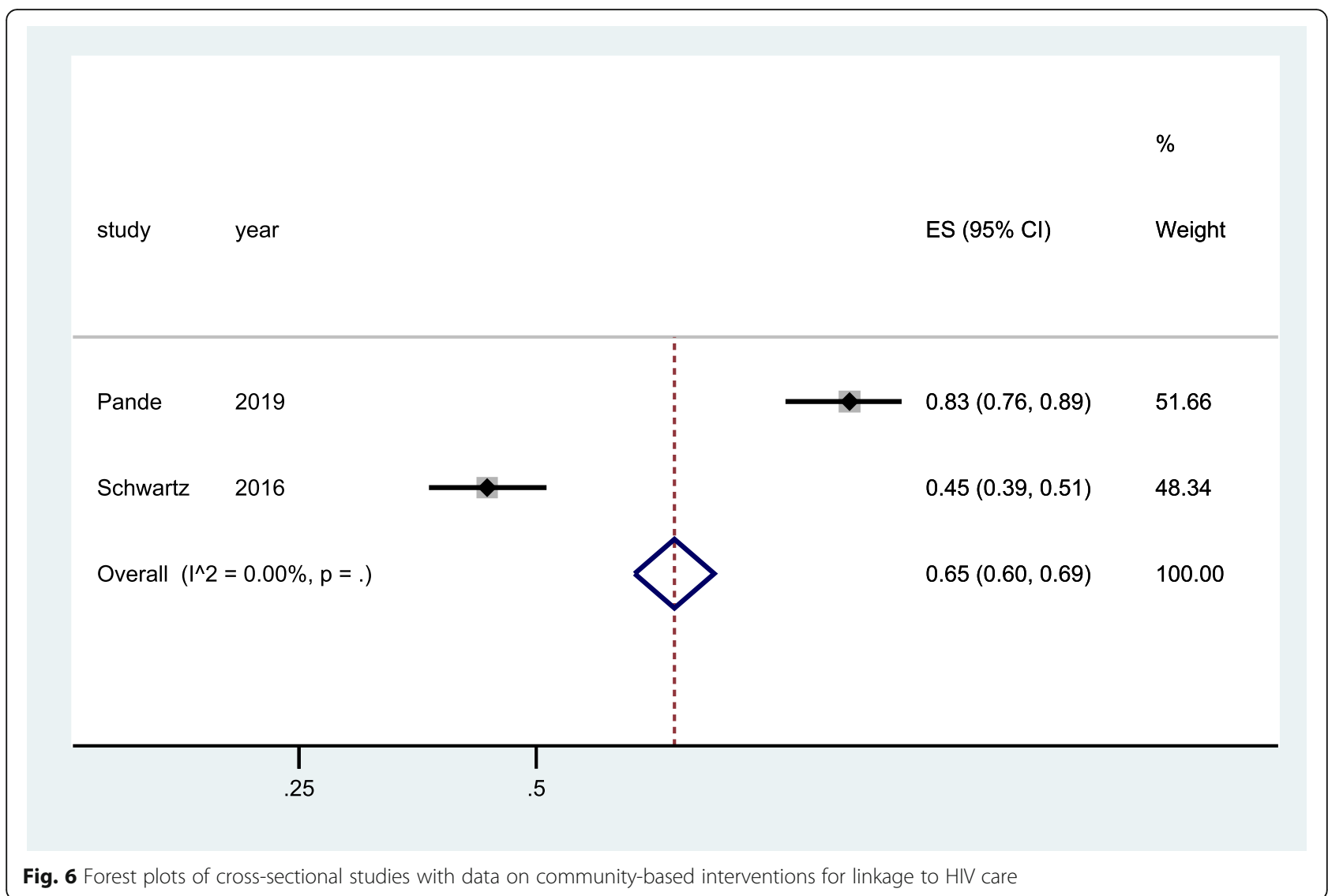

stigma and discrimination, violence prevention, and legal challenges associated with practicing sex work $[17,43,53$, 54]. Notably, it was not clear from this review if such interventions were integrated in the service provision for FSWs in hotspots and drop-in centers.

These findings also indicate that irregular and mobile provision of HIV services poses challenges of follow-up for linkage in care. Health workers may not maintain constant engagement with FSWs, and therefore, there is need for strengthening the community systems that allow health workers and peers to constantly engage and provide HIV services in the community for FSW.

\section{Use of antiretroviral therapy}

Similar to other outcomes, effective interventions for ART also provided a broad package of interventions, but the models in the specific packages varied for each outcome. For example, ART use was improved if interventions were provided in the static facility services based in hotspots, but the services had to be provided on a daily basis and on flex hours with room for phone consultation [42]. In addition, ART use was improved by interventions that had adherence support and use of text message follow-up as well as police sensitivity trainings to reduce violence [32, $35,46]$. However, increased ART use could not be sustained up to the end of the follow-up period [29, 32, 35]. Notably, we found only one country, Zimbabwe, that had national program with dedicated FSW clinics [46]. This finding implies that most of the interventions were on a small-scale and research-based with limited resources, and this could possibly explain why increased ART use was not sustained among FSWs.

Attaining short-term ART use by FSW has been reported in another systematic review [55], where it is indicated that $10 \%$ of FSW were stopping ART every year and cumulatively the proportions of ART interruption would increase. These findings imply that, for sustained ART use, a combination of behavioral-, biomedical-, and structural-related strategies should be uniquely tailored to the needs and priorities of FSWs and implemented as part of the established health systems with adequate financing.

\section{Viral suppression}

In this review, all the programs whose primary outcome was to improve viral suppression implemented 


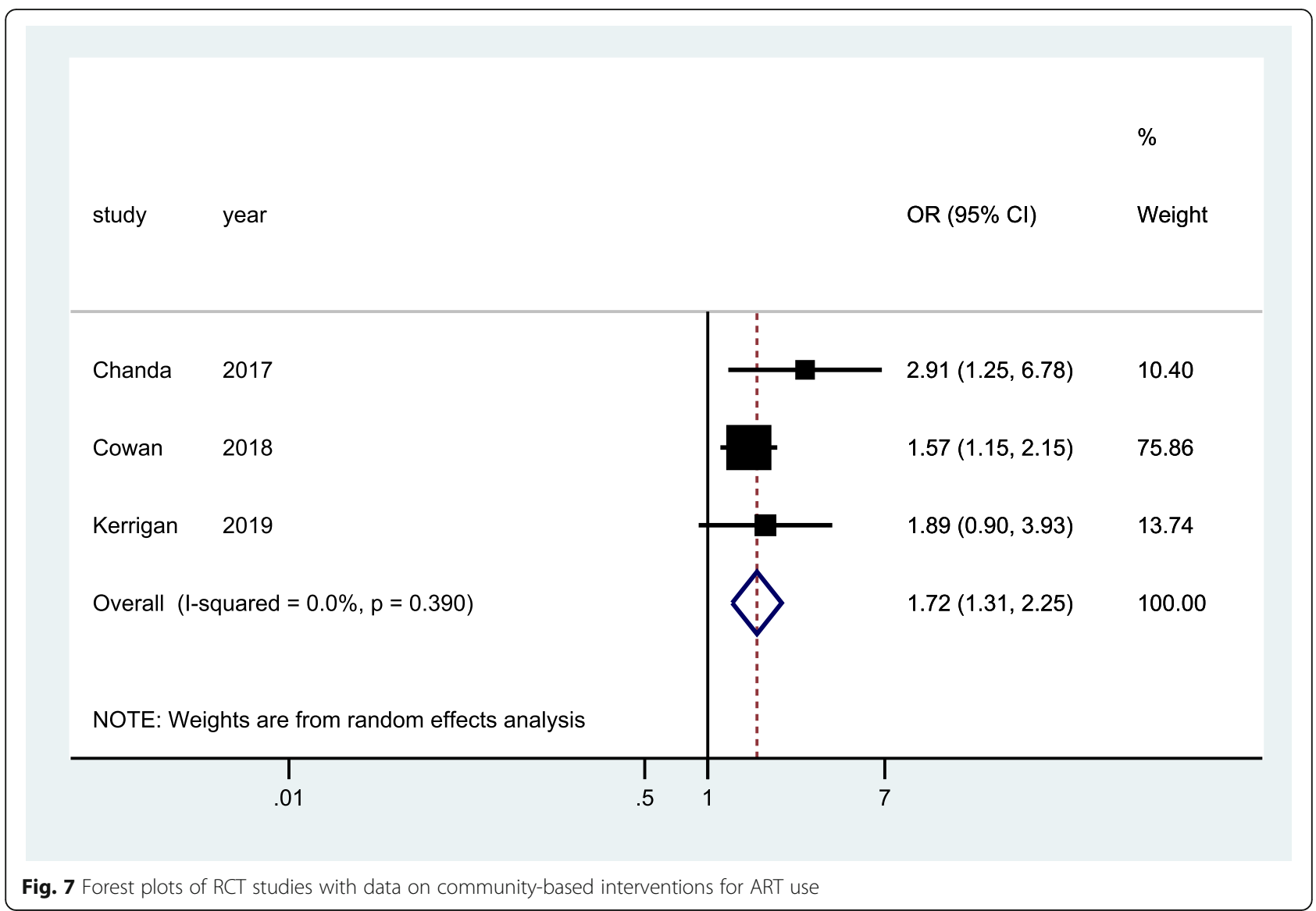

interventions that strengthened engagement in HIV care by FSWs; however, they did not lead to significant reduction in viral loads [32, 35, 40]. Although nonsignificant, the effect showed a positive trend of undetectable viral load suppression resulting from the exposure to the interventions. Failure to attain significant improvements in viral load suppression could have been due to gaps in community systems for supporting adherence to ART reported in some of the studies [32, 40]. The challenges of improving viral load suppression among FSWs have been reported in various research intervention studies. For example, studies conducted in sub-Saharan Africa reported that only 40 to $82 \%$ of FSW achieved viral suppression after exposure to various intervention programs $[33,56,57]$.

One of the studies in this review compared the progression of viral load suppression between young FSWs aged 18-24 years and FSWs older than 25 years. Seventy-eight percent (78\%) of the older FSWs attained higher rates of viral suppression, compared to $62 \%$ young FSWs. Young FSWs face unique underlying social and structural problems than older FSWs, such as more severe social and economic challenges, child protection issues, and mistrust and competition among older and young FSWs, a situation that may hinder access to services designed for adult FSWs [58-60].

These findings indicate that FSWs have varying challenges within their subgroups, and as such, interventions must consider the unique needs of different subgroups of FSWs. For example, programs must conduct intentional engagement of segments or subgroups of FSWs in designing and planning interventions. There should be optimal involvement of FSWs in activities such as mapping hotspots, identifying the FSW categories working in specific areas, assessing their risk and tailoring interventions according to the risks. This will enable implementation of interventions that are likely to be more effective along all the stages of HIV care cascade and lead to the ultimate goal of viral suppression and improved quality of life.

\section{Limitations of the study}

In this review, only one quasi-experimental study was included. Inclusion of only one type of design and comparing it with RCTs and observational designs may bias the overall effect. Above all, quasi-experimental designs 


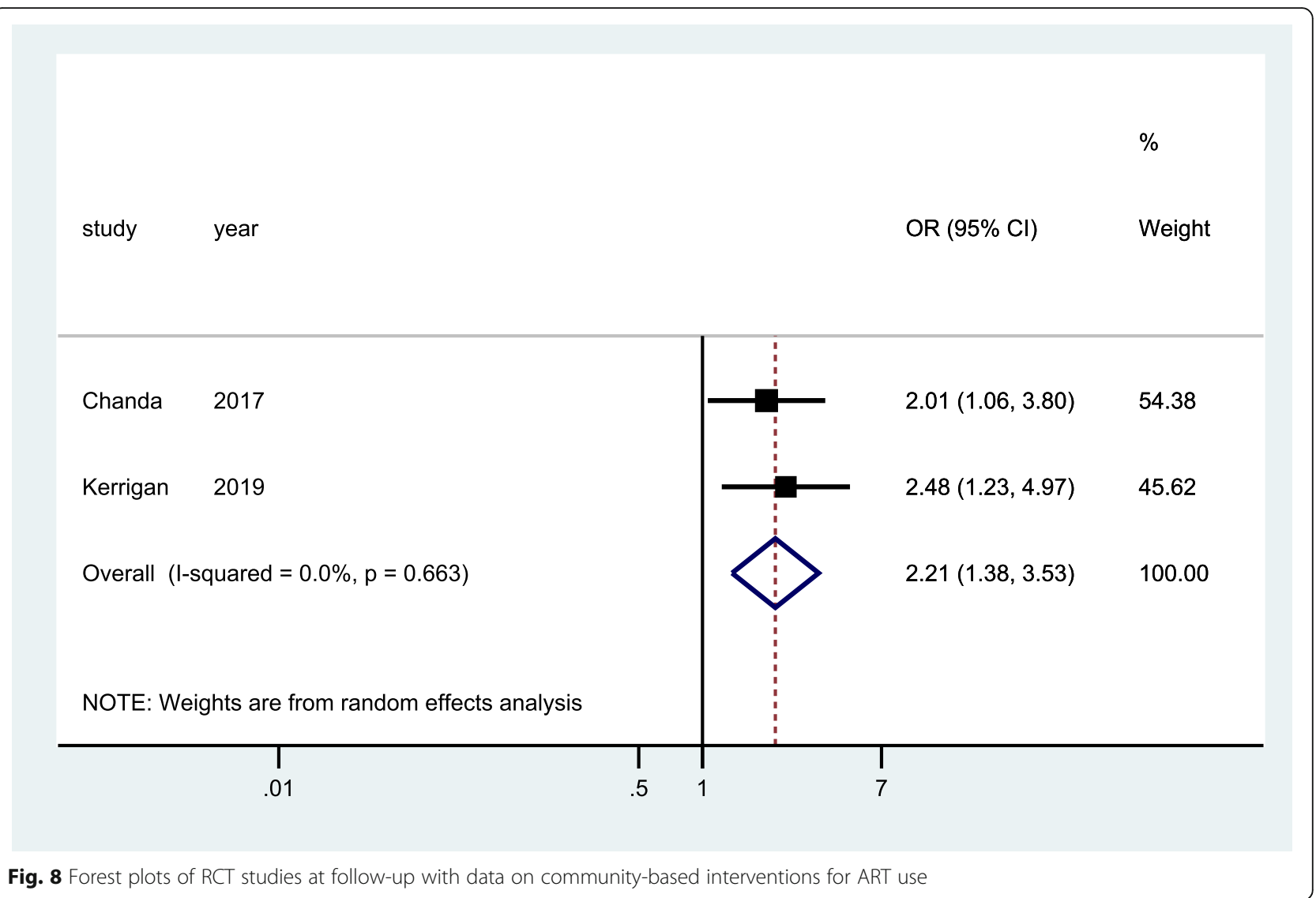

do not eliminate the problem of confounding variables. Indeed, while all other studies in this review showed no difference in the diagnosis outcome, we only observed a positive effect on the quasi study design. The results of diagnosis could be due to the fact that participants allocated to the different models of interventions were somewhat dissimilar. Further, in this review, we included studies whose primary aim was not to measure the effect of community intervention models, but rather we considered the reported results of our outcome of interest. For such studies, the effect may have been under or overestimated since critical observations on the processes of implementation were not emphasized. Finally, out of the 18 studies included in this review, only four were RCTs; we may therefore be underpowered to conclude on which models in community-based interventions were more effective than the others.

\section{Conclusion}

Overall, the evidence brought forward from this review shows that the effects of community-based interventions vary across the different stages of HIV care cascade. A broad package of interventions including a combination of behavioral, biomedical, and structural, designed with specific strategies, unique to each cascade stage appear to be more effective. Data suggests that there are limited community-based interventions that increase HIV diagnosis; however, a number of interventions are effective for HIV testing and ART use and can also increase linkage to care and viral suppression although not significantly. This review also found that the positive effects of community interventions to increasing cascade outcomes are short term, and the implementation is mostly done in research settings. As such, the information on long-term treatment outcomes and the extent to which FSWs link to, adhere on ART and get virally suppressed is sparse.

This review observed challenges related to expanding the community-based interventions for FSWs, as majority of interventions were small scale. Considerations for governments to strengthen support and integrate community-based HIV services in the mainstream health system are paramount. As countries roll out differentiated service delivery models, the health systems need to focus on provision of sustainable equitable care for all subgroups of FSWs. This can however be effective if 


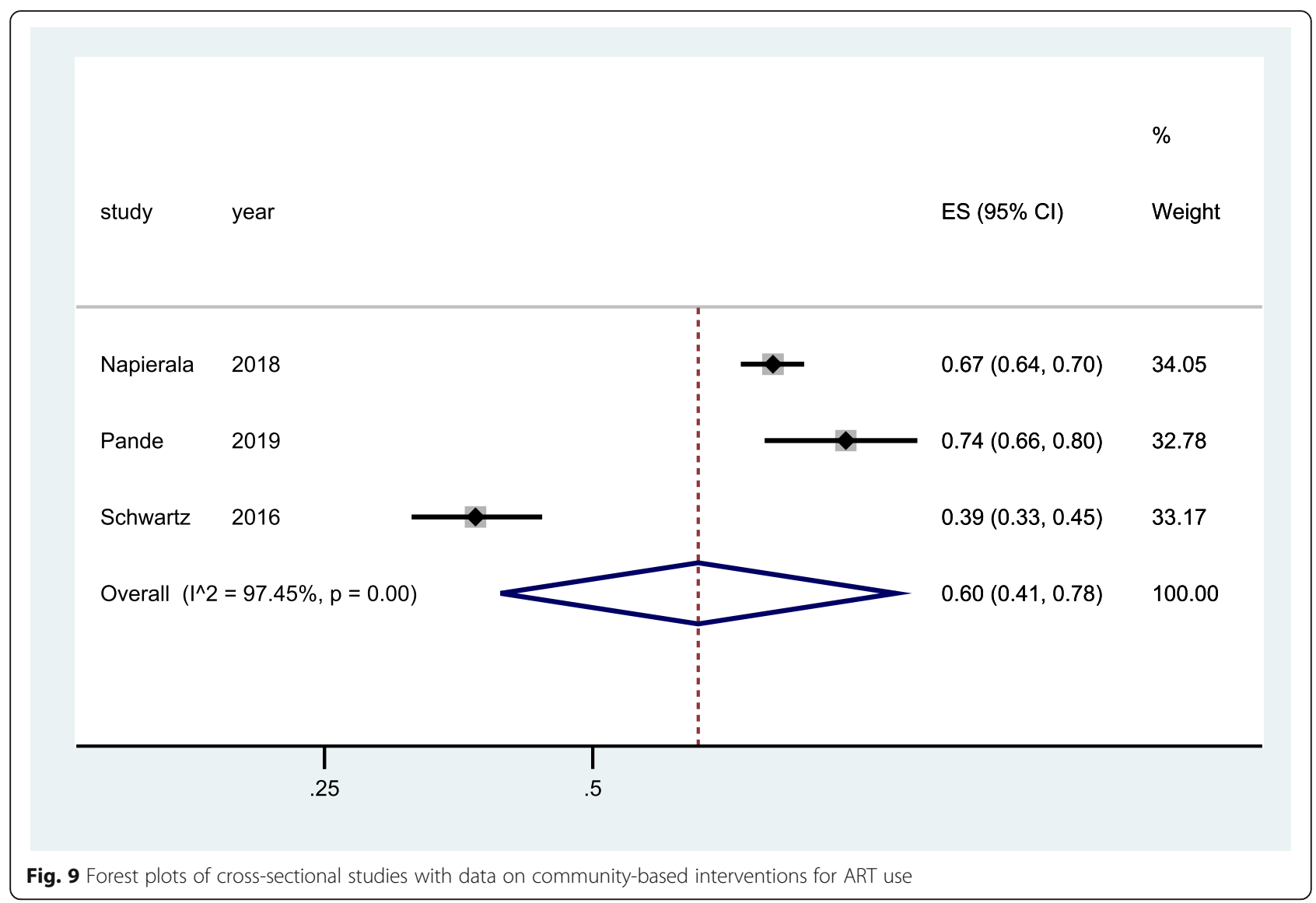

Table 3 A summary of reported outcomes across the care and treatment cascade for included studies

\begin{tabular}{|c|c|c|c|c|c|}
\hline (\#Ref) Author (year) & HIV testing & HIV diagnosis & Linkage to care & ART use & Viral suppression \\
\hline [28] Aho et al. (2012) & $\sqrt{ }$ & $\sqrt{ }$ & & & \\
\hline [29] Chanda et al. (2017) & & $\sqrt{ }$ & $\sqrt{ }$ & $\sqrt{ }$ & \\
\hline [30] Cowan et al. (2019) & $\sqrt{ }$ & $\sqrt{ }$ & & $\sqrt{ }$ & $\sqrt{ }$ \\
\hline [32] Cowan et al. (2018) & & $\sqrt{ }$ & & $\sqrt{ }$ & $\sqrt{ }$ \\
\hline [33] Huet et al. (2011) & & $\sqrt{ }$ & & $\sqrt{ }$ & $\sqrt{ }$ \\
\hline [34] Kelvin et al. (2019) & $\sqrt{ }$ & & & & $\sqrt{ }$ \\
\hline [35] Kerrigan et al. (2019) & $\sqrt{ }$ & & & & \\
\hline [36] Lafort et al. (2018) & & & $\sqrt{ }$ & $\sqrt{ }$ & $\sqrt{ }$ \\
\hline [36] Lafort et al. (2018) & $\sqrt{ }$ & & $\sqrt{ }$ & & \\
\hline [37] Lillie et al. (2019) & $\sqrt{ }$ & $\sqrt{ }$ & & & \\
\hline [38] Lafort et al. (2016) & & $\sqrt{ }$ & & $\sqrt{ }$ & \\
\hline [39] Luchters et al. (2008) & & $\sqrt{ }$ & & & \\
\hline [40] Napierala et al. (2018) & $\sqrt{ }$ & $\sqrt{ }$ & & $\sqrt{ }$ & $\sqrt{ }$ \\
\hline [47] Ndori-mharadze et al. (2018) & & $\sqrt{ }$ & & $\sqrt{ }$ & \\
\hline [42] Pande et al. (2019) & $\sqrt{ }$ & $\sqrt{ }$ & $\sqrt{ }$ & $\sqrt{ }$ & \\
\hline [43] Schwartz et al. (2017) & & $\sqrt{ }$ & $\sqrt{ }$ & $\sqrt{ }$ & \\
\hline [44] Tun et al. (2019) & & & $\sqrt{ }$ & $\sqrt{ }$ & \\
\hline [45] Vu et al. (2020) & & $\sqrt{ }$ & $\sqrt{ }$ & & \\
\hline
\end{tabular}


program data on FSW care cascade is actively collected and reported to inform programming for HIV services targeting FSWs. Further, there is need to conduct sufficiently powered research on the effectiveness of community-based interventions on the HIV care cascade for FSWs, to identify evidence-based optimal interventions and components and guide resource allocation.

\begin{abstract}
Abbreviations
AIDS: Acquired immune deficiency syndrome; ART: Antiretroviral therapy; CINAHL: Cumulative Index of Nursing and Allied Health Literature; EMBASE: Excerpta Medica database; FSW: Female sex workers; GRADE: Grading of Recommendations Assessment Development and Evaluation; HIV: Human immunodeficiency virus; IAS: International AIDS Society; ICASA: International Conference on HIV/AIDS and Sexually Transmitted Infections in Africa; KP: Key populations; MEDLINE: Medical Literature Analysis and Retrieval System Online; $\mathrm{MOH}$ : Ministry of Health; NOS: New Castle Ottawa scale; PRISMA-P: Preferred Reporting Items for Systematic Reviews and Meta-Analysis Protocols; PROSPERO: Prospective Register of Systematic Reviews; PubMed: Public/Publisher MEDLINE; ROBINSI: Risk of Bias in Non-Randomized Studies of Interventions; SSA: Sub-Saharan Africa; STls: Sexual transmitted infections; UAC: Uganda AIDS Commission; UNAIDS: United Nations Programme on HIV/AIDS; WHO: World Health Organization
\end{abstract}

\section{Acknowledgements}

We would like to thank Dr Vittoria Lutje for the support in developing and reviewing the search strategy for this systematic review.

\section{Authors' contributions}

LA conceptualized the study; LA and OA extracted and analyzed the data $L A, O A$, and $P N$ interpreted the statistical output of the results; LA drafted the manuscript; CS, OA, and PN reviewed the manuscript drafts and provided critical intellectual input. All authors read and approved the final manuscript.

\section{Funding}

This work received no specific grant from any funding agency in the public commercial, or not-for-profit sectors.

\section{Availability of data and materials}

All data generated or analyzed during this study are included in this manuscript.

\section{Declarations}

Ethics approval and consent to participate

Not applicable

\section{Consent for publication}

Not applicable

\section{Competing interests}

The authors declare that they have no competing interests.

\section{Author details}

'Division of Epidemiology \& Biostatistics, Faculty of Medicine and Health Sciences, Stellenbosch University, Cape Town, South Africa. ${ }^{2}$ DSI-NRF Centre of Excellence in Epidemiological Modelling and Analysis (SACEMA), Stellenbosch University, Stellenbosch, South Africa. ${ }^{3}$ Cochrane South Africa, South African Medical Research Council, Cape Town, South Africa. ${ }^{4}$ School of Nursing and Midwifery, Aga Khan University, Nairobi, Kenya. ${ }^{5}$ Department of Population Health, Aga Khan University, Nairobi, Kenya. ${ }^{6}$ School of Public Health, Faculty of Medicine and Health Sciences, University of the Witwatersrand, Johannesburg, South Africa.
Received: 17 November 2020 Accepted: 26 April 2021

Published online: 06 May 2021

\section{References}

1. UNAIDS. UNAIDS data 2019. Joint United Nations Programme on HIV/AIDS. Geneva: UNAIDS/JC2910E; 2019.

2. WHO. Consolidated guidelines on the use of antiretroviral drugs for treating and preventing HIV infection: recommendations for a public health approach. 2nd ed. Geneva: World Health Organization; 2016.

3. Baral S, Beyrer C, Muessig K, Poteat T, Wirtz AL, Decker MR, et al. Burden of HIV among female sex workers in low-income and middle-income countries: a systematic review and meta-analysis. Lancet Infect Dis. 2012; 12(7):538-49. https://doi.org/10.1016/S1473-3099(12)70066-X.

4. Uganda AIDS Commission. The Uganda HIV and AIDS country progress report. Kampala: Uganda AIDS Commission; 2016.

5. UNAIDS. UNAIDS Data Book. 2017 https://www.unaids.org/sites/default/files/ media_asset/20170720_Data_book_2017_en.pdf.

6. Prüss-Ustün A, Wolf J, Driscoll T, Degenhardt L, Neira M, Calleja JMG. HIV due to female sex work: regional and global estimates. PLoS One. 2013;8(5): e63476. https://doi.org/10.1371/journal.pone.0063476.

7. Macdonald V, Verster A, Baggaley R. A call for differentiated approaches to delivering HIV services to key populations. J Int AIDS Soc. 2017;20(Suppl 4): 21658. https://doi.org/10.7448/IAS.20.5.21658.

8. Matovu JK, Ssebadduka N. Knowledge, attitudes \& barriers to condom use among female sex workers and truck drivers in Uganda: a mixed-methods study. Afr Health Sci. 2013:13(4):1027-33. https://doi.org/10.4314/ahs.v13i4.24.

9. Decker MR, Wirtz AL, Moguilnyi V, Peryshkina A, Ostrovskaya M, Nikita M, et al. Female sex workers in three cities in Russia: HIV prevalence, risk factors and experience with targeted HIV prevention. AIDS Behav. 2014;18(3):56272. https://doi.org/10.1007/s10461-013-0577-y.

10. World Health Organization. Key considerations for differentiated antiretroviral therapy delivery for specific populations: children, adolescents, pregnant and breastfeeding women and key populations: World Health Organization; 2017. https://www.who.int/hiv/pub/arv/hiv-differentiated-caremodels-key-populations/en/.

11. Dhana A, Luchters S, Moore L, Lafort Y, Roy A, Scorgie F, et al. Systematic review of facility-based sexual and reproductive health services for female sex workers in Africa. Glob Health. 2014;10(1):46. https://doi.org/10.1186/1 744-8603-10-46.

12. Kerrigan DL, Fonner VA, Stromdahl S, Kennedy CE. Community empowerment among female sex workers is an effective HIV prevention intervention: a systematic review of the peer-reviewed evidence from lowand middle-income countries. AIDS Behav. 2013;17(6):1926-40. https://doi. org/10.1007/s10461-013-0458-4.

13. Ortblad KF, Oldenburg CE. Tailoring combination HIV prevention for female sex workers. Lancet HIV. 2018;5(8):e406-e7. https://doi.org/10.1016/S2352-3 018(18)30136-X.

14. Kerrigan DL, Fonner VA, Stromdahl S, Kennedy CE. Community empowerment among female sex workers is an effective HIV prevention intervention: a systematic review of the peer-reviewed evidence from lowand middle-income countries. AIDS Behav. 2013;17(6):1926-40. https://doi. org/10.1007/s10461-013-0458-4.

15. Maheu-Giroux M, Vesga JF, Diabaté $S$, Alary M, Baral $S$, Diouf $D$, et al. Population-level impact of an accelerated HIV response plan to reach the UNAIDS 90-90-90 target in Cote d'Ivoire: insights from mathematical modeling. PLoS Med. 2017;14(6):e1002321. https://doi.org/10.1371/journal. pmed.1002321.

16. Chersich MF, Luchters S, Ntaganira I, Gerbase A, Lo YR, Scorgie F, et al. Priority interventions to reduce HIV transmission in sex work settings in subSaharan Africa and delivery of these services. J Int AIDS Soc. 2013;16(1): 17980. https://doi.org/10.7448/IAS.16.1.17980.

17. Kerrigan D, Kennedy CE, Morgan-Thomas R, Reza-Paul S, Mwangi P, Win KT, et al. A community empowerment approach to the HIV response among sex workers: effectiveness, challenges, and considerations for implementation and scale-up. Lancet (London, England). 2015;385(9963):172-85

18. Rehle T, Saidel T, Mills S, Magnani R. Evaluating programs for HIV/AIDS prevention and care in developing countries. In: A handbook for program managers and decision makers. Washington: Family Health International; 2001.

19. Centres for Disease Control and Prevention (CDC). Occupational HIV transmission and prevention among health care workers. 2011. Retrieved October. 2011;30 
20. Egger M, Boulle A, Schechter M, Miotti P. Antiretroviral therapy in resourcepoor settings: scaling up inequalities? Int J Epidemiol. 2005;34(3):509-12. https://doi.org/10.1093/ije/dyi110.

21. Moore L, Chersich MF, Steen R, Reza-Paul S, Dhana A, Vuylsteke B, et al. Community empowerment and involvement of female sex workers in targeted sexual and reproductive health interventions in Africa: a systematic review. Glob Health. 2014;10(1):1-17.

22. Atuhaire L, Adetokunboh O, Shumba C, Nyasulu PS. Effect of female sex work-targeted community-based interventions along the HIV treatment cascade in sub-Saharan Africa: a systematic review protocol. BMJ Open. 2020;10(10):e039495. https://doi.org/10.1136/bmjopen-2020-039495.

23. Spicer CM, Ford MA. Monitoring HIV care in the United States: indicators and data systems; 2012.

24. Kay ES, Batey DS, Mugavero MJ. The HIV treatment cascade and care continuum: updates, goals, and recommendations for the future. AIDS Res Ther. 2016;13(1):1-7.

25. Control CfD, Prevention. Understanding the HIV care continuum. 2018 Retrieved October. 2018;1.

26. Higgins JP, Altman DG, Gøtzsche PC, Jüni $P$, Moher D, Oxman AD, et al. The Cochrane Collaboration's tool for assessing risk of bias in randomised trials. BMJ (Clinical research ed). 2011;343:d5928.

27. Wells GA, Shea B, O'Connell D, Peterson J, Welch V, Losos M, et al. The Newcastle-Ottawa Scale (NOS) for assessing the quality of nonrandomised studies in meta-analyses. Oxford; 2000. https://www.scienceopen.com/ document?vid=54b48470-4655-4081-b5d4-e8ebe8d1792e. Accessed Aug 2020.

28. Aho J, Nguyen VK, Diakité S, Sow A, Koushik A, Rashed S. High acceptability of HIV voluntary counselling and testing among female sex workers: impact of individual and social factors. HIV Med. 2012;13(3):156-65. https://doi.org/1 0.1111/j.1468-1293.2011.00951.x.

29. Chanda MM, Ortblad KF, Mwale M, Chongo S, Kanchele C, Kamungoma N, et al. HIV self-testing among female sex workers in Zambia: a cluster randomized controlled trial. PLoS Med. 2017;14(11):e1002442. https://doi. org/10.1371/journal.pmed.1002442.

30. Cowan FM, Chabata ST, Musemburi S, Fearon E, Davey C, Ndori-Mharadze T, et al. Strengthening the scale-up and uptake of effective interventions for sex workers for population impact in Zimbabwe. J Int AIDS Soc. 2019;22: e25320.

31. Cowan FM, Davey CB, Fearon E, Mushati P, Dirawo J, Cambiano V, et al. The HIV care cascade among female sex workers in Zimbabwe: results of a population-based survey from the sisters antiretroviral therapy programme for prevention of HIV, an integrated response (SAPPH-IRe) trial. JAIDS J Acquir Immune Defic Syndr. 2017;74(4):375-82. https://doi.org/10.1097/QAI. 0000000000001255.

32. Cowan FM, Davey C, Fearon E, Mushati P, Dirawo J, Chabata S, et al. Targeted combination prevention to support female sex workers in Zimbabwe accessing and adhering to antiretrovirals for treatment and prevention of HIV (SAPPH-IRe): a cluster-randomised trial. Lancet HIV. 2018; 5(8):e417-e26. https://doi.org/10.1016/\$2352-3018(18)30111-5.

33. Huet C, Ouedraogo A, Konaté I, Traore I, Rouet F, Kaboré A, et al. Long term virological, immunological and mortality outcomes in a cohort of HIVinfected female sex workers treated with highly active antiretroviral therapy in Africa. BMC Public Health. 2011;11(1):700. https://doi.org/10.1186/1471-24 58-11-700

34. Kelvin EA, George G, Mwai E, Kinyanjui S, Romo ML, Odhiambo JO, et al. A randomized controlled trial to increase HIV testing demand among female sex workers in Kenya through announcing the availability of HIV self-testing via text message. AIDS Behav. 2019;23(1):116-25. https://doi.org/10.1007/s1 0461-018-2248-5.

35. Kerrigan D, Mbwambo J, Likindikoki S, Davis W, Mantsios A, Beckham SW et al. Project Shikamana: community empowerment-based combination HIV prevention significantly impacts HIV incidence and care continuum outcomes among female sex workers in Iringa, Tanzania. JAIDS J Acquir Immune Defic Syndr. 2019;82(2):141-8. https://doi.org/10.1097/QAl. 0000000000002123.

36. Lafort $Y$, Greener L, Lessitala F, Chabeda S, Greener R, Beksinska M, et al. Effect of a 'diagonal' intervention on uptake of HIV and reproductive health services by female sex workers in three sub-Saharan African cities. Tropical Med Int Health. 2018;23(7):774-84. https://doi.org/10.1111/tmi.13072.

37. Lillie TA, Persaud NE, DiCarlo MC, Gashobotse D, Kamali DR, Cheron M, et al. Reaching the unreached: performance of an enhanced peer outreach approach to identify new HIV cases among female sex workers and men who have sex with men in HIV programs in West and Central Africa. PLoS One. 2019;14(4):e0213743. https://doi.org/10.1371/journal.pone.0213743.

38. Lafort Y, Greener R, Roy A, Greener L, Ombidi W, Lessitala F, et al. HIV prevention and care-seeking behaviour among female sex workers in four cities in India, Kenya, Mozambique and South Africa. Trop Med Int Health. 2016;21(10):1293-303. https://doi.org/10.1111/tmi.12761.

39. Luchters S, Chersich MF, Rinyiru A, Barasa M-S, King'ola N, Mandaliya K, et al. Impact of five years of peer-mediated interventions on sexual behavior and sexually transmitted infections among female sex workers in Mombasa, Kenya. BMC Public Health. 2008;8(1):143. https://doi.org/10.1186/1471-24588-143.

40. Napierala S, Chabata ST, Fearon E, Davey C, Hargreaves J, Busza J, et al. Engagement in HIV care among young female sex workers in Zimbabwe. JAIDS J Acquir Immune Defic Syndr. 2018;79(3):358-66. https://doi.org/10.1 097/QAl.0000000000001815.

41. Ndori-Mharadze T, Fearon E, Busza J, Dirawo J, Musemburi S, Davey C, et al. Changes in engagement in HIV prevention and care services among female sex workers during intensified community mobilization in 3 sites in Zimbabwe, 2011 to 2015. J Int AIDS Soc. 2018;21:e25138. https://doi.org/1 0.1002/jia2.25138.

42. Pande G, Bulage L, Kabwama S, Nsubuga F, Kyambadde P, Mugerwa S, et al. Preference and uptake of different community-based HIV testing service delivery models among female sex workers along Malaba-Kampala highway, Uganda, 2017. BMC Health Serv Res. 2019;19(1):799. https://doi. org/10.1186/s12913-019-4610-3.

43. Schwartz S, Lambert A, Phaswana-Mafuya N, Kose Z, Mcingana M, Holland C, et al. Engagement in the HIV care cascade and barriers to antiretroviral therapy uptake among female sex workers in Port Elizabeth, South Africa: findings from a respondent-driven sampling study. Sex Transm Infect. 2017; 93(4):290-6. https://doi.org/10.1136/sextrans-2016-052773.

44. Tun W, Apicella L, Casalini C, Bikaru D, Mbita G, Jeremiah K, et al. Community-based antiretroviral therapy (ART) delivery for female sex workers in Tanzania: 6-month ART initiation and adherence. AIDS Behav. 2019;23(2):142-52. https://doi.org/10.1007/s10461-019-02549-x.

45. Vu L, Tun W, Apicella L, Casalini C, Makyao N, Tsang S, et al. Communitybased antiretroviral therapy (ART) delivery for female sex workers in Tanzania: intervention model and baseline findings. AIDS Care. 2020;32(6): 729-34. https://doi.org/10.1080/09540121.2019.1640846.

46. Napierala S, Chabata ST, Fearon E, Davey C, Hargreaves J, Busza J, et al. Engagement in HIV care among young female sex workers in Zimbabwe. J Acquir immune Defic Syndr (1999). 2018;79(3):358-66.

47. Ndori-Mharadze T, Fearon E, Busza J, Dirawo J, Musemburi S, Davey C, et al. Changes in engagement in HIV prevention and care services among female sex workers during intensified community mobilization in 3 sites in Zimbabwe, 2011 to 2015. J Int AIDS Soc. 2018;21 Suppl 5:e25138.

48. Woodford MR, Chakrapani V, Newman PA, Shunmugam M. Barriers and facilitators to voluntary HIV testing uptake among communities at high risk of HIV exposure in Chennai, India. Glob Public Health. 2016;11(3):363-79. https://doi.org/10.1080/17441692.2015.1057757.

49. Mehta SH, Lucas GM, Solomon S, Srikrishnan AK, McFall A, Nandagopal P, et al. HIV care cascade among hard to reach populations in India: need to expand HIV counseling and testing. Top Antivir Med. 2014;22(e-1):565.

50. Pines HA, Goodman-Meza D, Pitpitan EV, Torres K, Semple SJ, Patterson TL. HIV testing among men who have sex with men in Tijuana, Mexico: a crosssectional study. BMJ Open. 2016;4;6(2):e010388. https://doi.org/10.1136/ bmjopen-2015-010388.

51. Smyrnov P, Williams LD, Korobchuk A, Sazonova Y, Nikolopoulos GK, Skaathun B, et al. Risk network approaches to locating undiagnosed HIV cases in Odessa, Ukraine. J Int AIDS Soc. 2018;21(1):e25040. https://doi.org/1 0.1002/jia2.25040.

52. Rosenberg JS, Bakomeza D. Let's talk about sex work in humanitarian settings: piloting a rights-based approach to working with refugee women selling sex in Kampala. Reprod Health Matters. 2017;25(51):95-102. https:// doi.org/10.1080/09688080.2017.1405674.

53. Lancaster KE, Cernigliaro D, Zulliger R, Fleming PF. HIV care and treatment experiences among female sex workers living with HIV in sub-Saharan Africa: a systematic review. Afr J AIDS Res. 2016;15(4):377-86. https://doi. org/10.2989/16085906.2016.1255652.

54. Prakash R, Bhattacharjee P, Blanchard A, Musyoki H, Anthony J, Kimani J, et al. Effects of exposure to an intensive HIV-prevention programme on 
behavioural changes among female sex workers in Nairobi, Kenya. Afr J AIDS Res. 2018;17(2):99-108. https://doi.org/10.2989/16085906.2017.1377268.

55. Mountain E, Mishra S, Vickerman P, Pickles M, Gilks C, Boily M-C. Antiretroviral therapy uptake, attrition, adherence and outcomes among HIV-infected female sex workers: a systematic review and meta-analysis. PLoS One. 2014;9(9):e105645. https://doi.org/10.1371/journal.pone.0105645.

56. Konate I, Ouedraogo A, Sanon A, Diallo R, Ouedraogo J-L, Huet C, et al. Linking HIV prevention and care for community interventions among highrisk women in Burkina Faso-the ARNS 1222 "Yerelon" cohort. JAIDS J Acquir Immune Defic Syndr. 2011;57(Supplement 1):S50-S4. https://doi. org/10.1097/QAl.0b013e3182207a3f.

57. Donastorg Y, Barrington C, Perez M, Kerrigan D. Abriendo Puertas: baseline findings from an integrated intervention to promote prevention, treatment and care among FSW living with HIV in the Dominican Republic. PLoS One. 2014:9(2):e88157. https://doi.org/10.1371/journal.pone.0088157.

58. Zhang X-D, Temmerman M, Li Y, Luo W, Luchters S. Vulnerabilities, health needs and predictors of high-risk sexual behaviour among female adolescent sex workers in Kunming, China. Sex Transm Infect. 2013;89(3): 237-44. https://doi.org/10.1136/sextrans-2012-050690.

59. Inguane C, Horth RZ, Miranda AE, Young PW, Sathane I, Cummings BE, et al. Socio-demographic, behavioral and health characteristics of underage female sex workers in Mozambique: the need to protect a generation from HIV risk. AIDS Behav. 2015;19(12):2184-93. https://doi.org/10.1007/s10461-01 5-1068-0.

60. Delany-Moretlwe S, Cowan FM, Busza J, Bolton-Moore C, Kelley K, Fairlie L. Providing comprehensive health services for young key populations: needs, barriers and gaps. J Int AIDS Soc. 2015;18(2 Suppl 1):19833. https://doi.org/1 0.7448/IAS.18.2.19833.

\section{Publisher's Note}

Springer Nature remains neutral with regard to jurisdictional claims in published maps and institutional affiliations.

Ready to submit your research? Choose BMC and benefit from:

- fast, convenient online submission

- thorough peer review by experienced researchers in your field

- rapid publication on acceptance

- support for research data, including large and complex data types

- gold Open Access which fosters wider collaboration and increased citations

- maximum visibility for your research: over $100 \mathrm{M}$ website views per year

At $\mathrm{BMC}$, research is always in progress.

Learn more biomedcentral.com/submissions 